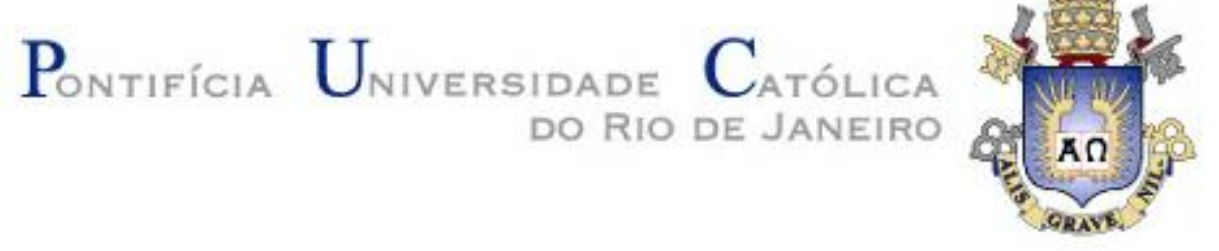

Vanessa da Silva Sá Sampaio Moreira

Geometria Fractal na Educação Básica

Dissertação apresentada ao Programa de Pós-Graduação em Matemática da PUC-Rio como requisito parcial para obtenção do grau de Mestre em Matemática (opção profissional).

Orientadora: Prof. Christine Sertã Costa

Rio de Janeiro

Setembro de 2017 


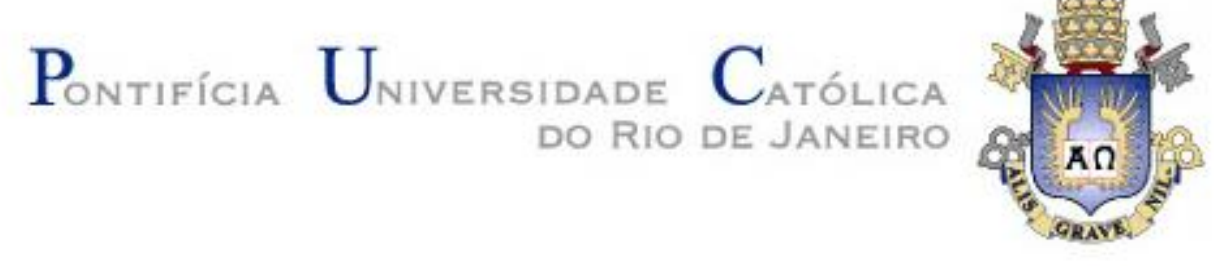

Vanessa da Silva Sá Sampaio Moreira

\title{
Geometria Fractal na Educação Básica
}

\begin{abstract}
Dissertação apresentada ao Programa de Pós-Graduação em Matemática da PUC-Rio como requisito parcial para obtenção do grau de Mestre em Matemática (opção profissional).
\end{abstract}

Prof ${ }^{a}$ Christine Sertã Costa

Orientadora

Departamento de Matemática - PUC-Rio

Prof. Sinésio Pesco

Departamento de Matemática - PUC-Rio

Prof. Alessandro Gaio Chimenton

Departamento de Matemática - PUC-Rio

Prof. Francisco Roberto Pinto Mattos

Departamento de Matemática e Desenho Geométrico

Instituto de aplicação/UERJ

Prof. Márcio da Silveira Carvalho

Coordenador Setorial do Centro

Técnico Científico - PUC-Rio

Rio de Janeiro, 04 de setembro de 2017 
Todos os direitos reservados. É proibida a reprodução total ou parcial do trabalho sem autorização da universidade, da autora e da orientadora.

\section{Vanessa da Silva Sá Sampaio Moreira}

Graduou-se em Licenciatura em Matemática pela Universidade

Federal Fluminense (UFF). Possui especialização em Psicopedagogia Institucional pela Universidade Veiga de Almeida (UVA). Trabalhou como professora nas redes privada e estadual do Rio de Janeiro. Atualmente faz parte do quadro efetivo de professores da rede municipal do Rio de Janeiro.

Ficha Catalográfica

Moreira, Vanessa da Silva Sá Sampaio

Geometria fractal na educação básica / Vanessa da Silva Sá Sampaio Moreira; orientadora: Christine Sertã Costa. 2017.

78 f.: il. color. ; $30 \mathrm{~cm}$

Dissertação (mestrado) - Pontifícia Universidade Católica do Rio de Janeiro, Departamento de Matemática, 2017.

Inclui bibliografia

1. Matemática - Teses. 2. Geometria fractal. 3. Fractais. 4. Educação matemática. 5. Ensino básico. I. Costa, Christine Sertã. II. Pontifícia Universidade Católica do Rio de Janeiro. Departamento de Matemática. III. Título. 
Para meus pais, tudo por eles e para eles. 


\section{Agradecimentos}

À CAPES, pelo incentivo financeiro. Ao PROFMAT e à PUC-Rio, pela administração do curso, bem como aos professores dos dois anos letivos.

À professora Christine, pela orientação paciente. Ao professor Sinésio, pela coordenação e cordialidade. Aos membros da banca, pela disponibilidade.

Aos colegas de turma, em especial o "Grupo do mal": Eduardo, Felipe, Keilla, Larissa, Patrícia, Sérgio e Waldeir. Uns ficaram no meio do caminho, mas não posso deixar de reconhecer o apoio que trocamos todo tempo que ficamos juntos. Ao Waldeir agradeço, especialmente, por ter feito os paralelepípedos.

Aos colegas de trabalho Marcus Vinicius, pela localização histórica nas biografias e postagem das atividades, Fernanda, pela tradução, Roberta, pelas concordâncias, por se dispor em revisar o texto e pela sensibilidade de sempre, e Ana Rosa, pelos dados quantitativos da escola.

Aos amigos de ideal espírita, que, mesmo na dificuldade, compreenderam meu momento. Em especial à Camila, por me ouvir e revisar o texto.

A todos os membros da família que torcem por mim e tantas vezes perguntaram como andavam as coisas. Alguns ajudaram diretamente e não posso deixar de especificar e agradecer por essas ajudas:

À minha prima Amanda, pelo estágio em formatação de dissertações. Aos meus padrinhos Bernardete e Jorge, por emprestarem a casa silenciosa, e Gilberto, por desligar ou diminuir o som e por ser expulso algumas vezes do atelier.

Aos meus sobrinhos Ana Carolina e Tarso, por ouvirem algumas vezes: "nesse dia não vai dar" ou "quando eu acabar o trabalho...". Alícia e Maria Alice também, que, apesar de não terem ouvido, passaram pelas mesmas consequências.

Por último, o mais importante: aos meus pais. Meu pai, Reginaldo, por estar sempre olhando por mim da erraticidade, e minha mãe, Arlete, pela mesma tarefa aqui na Terra, principalmente por atender meus pedidos de oração e aguentar meu desespero. Só tenho a agradecer aos dois, e agradecer é pouco. 


\section{Resumo}

Moreira, Vanessa da Silva Sá Sampaio; Costa, Christine Sertã. Geometria Fractal na Educação Básica. Rio de Janeiro, 2017. 78p. Dissertação de Mestrado - Departamento de Matemática, Pontifícia Universidade Católica do Rio de Janeiro.

A geometria fractal não é um conteúdo abordado usualmente na educação básica. O presente trabalho disserta sobre essa geometria, com o objetivo de divulgar e ampliar o conhecimento sobre ela, principalmente para professores que atuam nesse nível de escolaridade. É iniciado com um breve histórico do surgimento dos fractais, até sua definição formal, exibindo exemplos clássicos e uma pequena biografia de seus criadores. Em seguida, é apresentada uma seleção de conteúdos matemáticos que naturalmente podem ser trabalhados a partir dessa geometria. Algumas propostas de atividades que possuem fractais e podem ser aplicadas em diversos níveis da educação básica também são apresentadas. Por fim, é retratada a experiência da realização de uma das atividades propostas em uma turma de $9^{\circ}$ ano de uma escola pública do município do Rio de Janeiro. Acreditamos que a beleza e o apelo visual dos fractais atuem como elementos motivadores e inovadores para que temas importantes do currículo da educação básica sejam abordados de forma mais significativa.

\section{Palavras-chave}

Geometria Fractal; Fractais; Educação Matemática; Ensino Básico. 


\section{Abstract}

Moreira, Vanessa da Silva Sá Sampaio; Costa, Christine Sertã (Advisor). Fractal Geometry in Basic Education. Rio de Janeiro, 2017. 78p. Dissertação de Mestrado - Departamento de Matemática, Pontifícia Universidade Católica do Rio de Janeiro.

Fractal geometry is not a content usually addressed in basic education. This paper discusses this geometry with the purpose of disseminating and expanding knowledge about it, especially for teachers who work at this level of education. It begins with a brief history of the emergence of the fractals until its formal definition, exhibiting classic examples and a small biography of its creators. Then, we present a selection of mathematical contents of basic education that can, of course, be worked from this geometry. Some proposed activities that involve fractals and are suitable for applications at various levels of this school segment are also presented. Finally, the experience of one of the proposed activities in a 9th grade class of a public school in the city of Rio de Janeiro is portrayed. We believe that the beauty and visual appeal of fractals act as motivating and innovative elements for important themes in the basic education curriculum to be addressed in a more meaningful way.

\section{Keywords}

Fractal Geometry; Fractals; Mathematics Education; Basic Education. 


\section{Sumário}

1 Motivação e objetivos

2 Geometria Fractal 11

2.1. Surgimento e características 12

2.2. Alguns fractais clássicos 14

2.2.1. Conjunto de Cantor 14

2.2.2. Fractais de Koch 16

$\begin{array}{ll}\text { 2.2.3. Fractais de Sierpinski e Menger } & 17\end{array}$

2.2.4. Fractal de Mandelbrot 20

3 Seleção de conceitos matemáticos $\quad 25$

3.1. Perímetro e área de polígonos e circunferência 25

3.2. Área e volume de blocos retangulares 32

3.3. Progressões 33

3.4. Recorrências 40

4 Coletânea de atividades para a educação básica com características fractais $\quad 45$

4.1. Atividade 1: Conhecendo fractais 46

4.2. Atividade 2: Desenhando um fractal 49

4.3. Atividade 3: Pentágonos e estrelas inspirados em fractais 51

4.4. Atividade 4: Quadrados inspirados em fractais 54

4.5. Atividade 5: Circunferências inspiradas em fractais 58

4.6. Atividade 6: Paralelepípedos inspirados em fractais 61

5 Aplicação no ensino e resultados $\quad 64$

6 Considerações finais $\quad 70$

7 Referências bibliográficas $\quad 71$

8 Apêndices $\quad 72$ 
8.1. Sugestões de respostas para a atividade "Desenhando um fractal"

8.2. Sugestões de respostas para a atividade "Pentágonos e estrelas inspirados em fractais"

8.3. Sugestões de respostas para a atividade "Quadrados inspirados em fractais"

8.4. Sugestões de respostas para a atividade "Circunferências inspiradas em fractais"

8.5. Sugestões de respostas para a atividade "paralelepípedos inspirados em fractais" 


\section{1 \\ Motivação e objetivos}

Pode-se entender um fractal como um objeto geométrico que, ao ser dividido em várias partes, tem cada uma delas semelhante ao objeto original. A geometria fractal não é muito divulgada e não faz parte do currículo da educação básica. Esses motivos, acrescidos da possível falta de conhecimento ou das obrigações curriculares impostas no dia-a-dia da sala de aula, fazem com que esse assunto não seja explorado por grande parte dos docentes da educação básica no seu cotidiano escolar. Porém, diversos conteúdos matemáticos podem ser desenvolvidos através dos fractais. $O$ interesse pelo tema pode ser despertado não só pelo grande apelo visual através das belas imagens que essa geometria nos proporciona, mas também pela sua aplicabilidade em vários níveis de escolaridade.

O objetivo geral deste trabalho é apresentar o conceito da geometria fractal e alguns tópicos matemáticos que podem ser explorados a partir da mesma, estabelecendo uma conexão com os conteúdos da educação básica, ampliando, assim, sua divulgação. Mais especificamente, temos como objetivos:

$>$ Contextualizar e definir a geometria fractal.

$>$ Apresentar exemplos clássicos de fractais com breve biografia de seus autores.

Desenvolver alguns conteúdos matemáticos pertinentes ao tema.

> Sugerir atividades com fractais a professores da educação básica.

> Relatar a experiência de uma atividade aplicada no ensino fundamental de uma escola do município do Rio de Janeiro.

No capítulo a seguir, daremos início à contextualização histórica e caracterização da geometria dos fractais. 


\title{
2 \\ Geometria Fractal
}

Para introduzir o conceito da geometria fractal, é preciso compreender o significado de geometria.

A palavra geometria é formada por dois termos gregos: geo, que representa terra; e metria, que simboliza medida. A união desses termos constitui o sentido do vocábulo: "medida da terra" ou "medir a terra".

Segundo o dicionário Aurélio (2008), geometria é a "ciência que investiga as formas e dimensões dos seres matemáticos". Na prática, a geometria é uma parte da matemática que estuda as formas que ocupam um espaço e suas relações e examina as posições relativas entre essas formas, seus tamanhos e estruturas. Essas relações criam diversas propriedades, fazendo-se necessária a subdivisão dessa área de conhecimento. Dentre os diversos tipos de geometria existentes, podemos citar: euclidiana, analítica, plana, espacial, descritiva e hiperbólica. Umas mais clássicas, outras nem tanto.

Mesmo existindo tanta variedade de geometria, nenhuma delas consegue representar fielmente as formas da natureza.

\begin{abstract}
$\mathrm{Na}$ constituição de nosso mundo, da natureza em geral, por mares e oceanos, separando os continentes e ilhas, com suas costas, suas montanhas e rios, rochas, plantas e animais, e acimas as nuvens etc., temos componentes com suas formas nas quais dominam a irregularidade e o caos; tentar simplificálas, empregando formas usuais da clássica geometria euclidiana, como triângulo, círculos, esferas, cones, etc., seria absurdamente inadequado. A geometria dos fractais pode fornecer aproximações para essas formas. (BARBOSA, 2005, p. 10).
\end{abstract}

Portanto, tais aproximações foram inspirações para a criação da geometria fractal, pois é a que mais se aproxima da modelagem natural perfeita.

A seguir procuramos construir o avanço histórico do surgimento dessa geometria, listar as características de um fractal e explicitar outras definições que contribuem para a fundamentação do tema. 


\section{1. \\ Surgimento e características}

Ao longo do tempo, vários modelos de fractais foram construídos por matemáticos, mas não possuíam essa designação e não foram desenvolvidos como tais. Geralmente eram figuras que não se encaixavam nas geometrias tradicionais. A Curva de Koch e o Triângulo de Sierpinski são exemplos disso. Ao longo do capítulo, esses e outros modelos de fractais serão melhor abordados.

Em 1961, Benoit Mandelbrot, matemático polonês, trabalhando na IBM nos Estados Unidos, encontrou problemas nas linhas telefônicas da empresa - eram ruídos que atingiam a comunicação dos computadores. Os profissionais da área já tinham desistido de buscar solução devido à irregularidade dos sons. Mandelbrot ajudou a resolver o problema, considerando os erros de transmissão como um "Conjunto de Cantor", trabalho elaborado por Georg Cantor, datado de 1883. Esse estudo é mais um exemplo dos primeiros representantes da geometria fractal que não eram classificados como tal, na época, e será tratado adiante.

Assim seguiu Mandelbrot: procurando situações e modelos nos quais ele pudesse aplicar suas ideias. Passou a analisar formas geométricas que possuíam as mesmas propriedades: infinitude, que é a manutenção infinita de um padrão, e autossemelhança, que é a semelhança do objeto original com suas partes. Denominou essas formas de fractais. Para criar o nome, ele se fundamentou no adjetivo latino fractus, do verbo frangere, que significa quebrar.

De acordo com Barbosa (2005, p. 12), "a geometria fractal de Mandelbrot reflete uma natureza de irregularidades, de reentrâncias, saliências e depressões, de fragmentação".

Assim, a geometria fractal (ou geometria dos fractais) pode ser entendida como uma área da matemática que estuda as características e o comportamento dos fractais, que são abstratas formas geométricas que seguem um mesmo modelo de maneira infinita, ainda que limitados a uma área finita.

No decorrer de suas pesquisas, Mandelbrot observou que algumas formas existentes na natureza apresentavam atributos fractais. O repolho, folhas de determinadas plantas, galhos de árvore, asas de algumas aves, os neurônios e os vasos sanguíneos são exemplos desses fractais naturais. Ao separá-los em vários pedaços, eles se parecem com o objeto original, ou seja, são autossemelhantes. 
A figura 1 ilustra imagens com alguns recortes, nos quais podemos observar a autossemelhança dos exemplos citados.

Figura 1 - Imagens da natureza e recortes semelhantes.

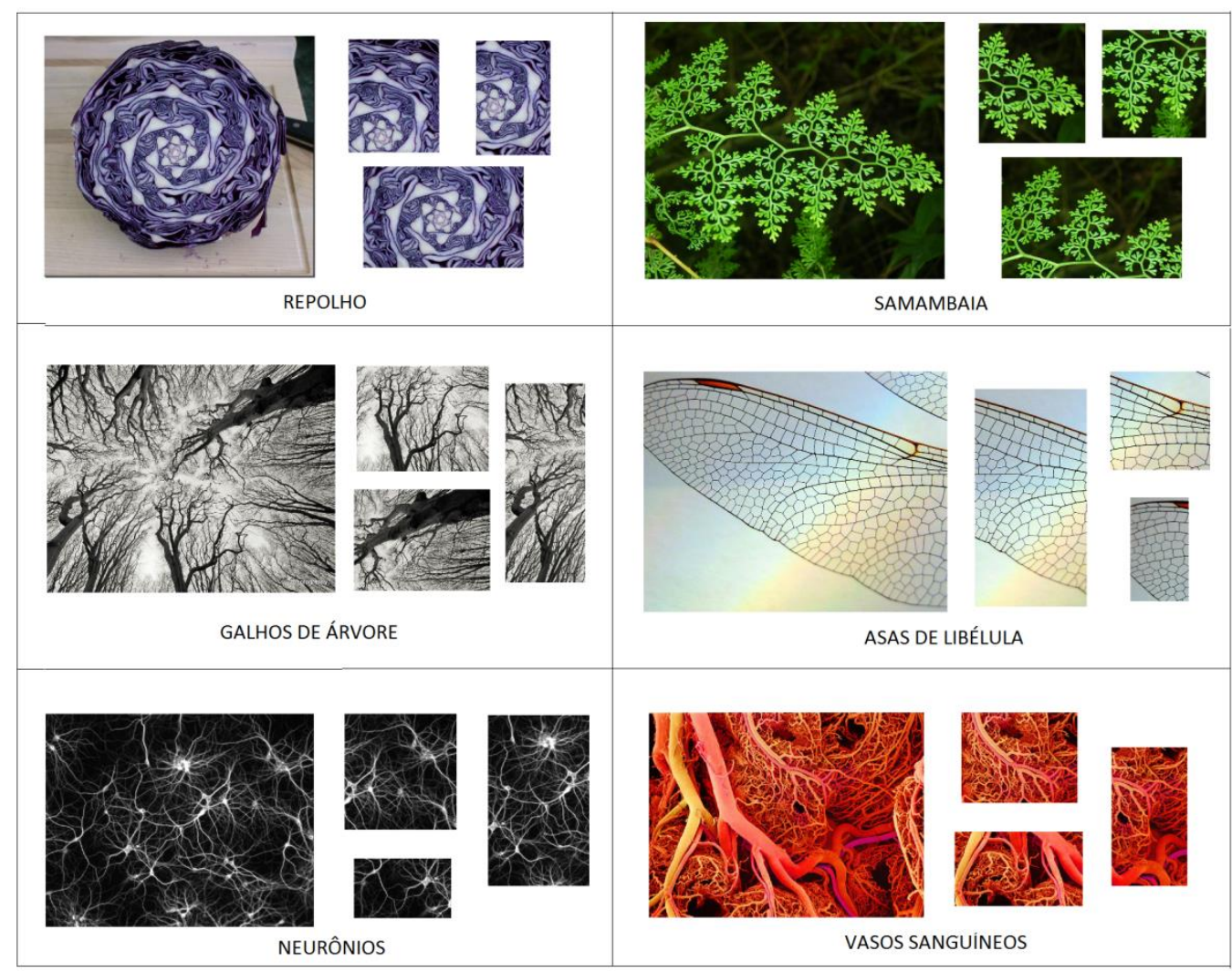

Fonte: www.mdig.com.br, acesso em 5 de janeiro de 2017. Composição própria.

Nas últimas décadas do século $X X$, através dessa nova relação geométrica com a natureza, os cientistas passaram a compreender melhor 0 desenvolvimento e a estrutura das paisagens, animais e seres humanos, pois havia uma maneira mais satisfatória de representá-los, já que, no universo, quase nenhuma forma é regular. Foi uma transformação científica.

Logo, a geometria fractal também pode ser vista como "uma linguagem matemática que descreve, analisa e modela as formas encontradas na natureza." (JANOS, 2008, p. 10).

Serão apresentados, a seguir, modelos que correspondem a alguns exemplos clássicos dessa geometria e como foram construídos. Além disso, apresentamos uma pequena biografia de seus autores. 


\section{2.}

\section{Alguns fractais clássicos}

Ao criarem modelos de fractais, Cantor, Koch e Sierpinski não tinham essa intenção. As figuras foram construídas por esses matemáticos em seus estudos particulares não relacionados ao tema. Com a estruturação da geometria fractal estabelecida por Mandelbrot, foi possível mostrar que essas imagens constituíam amostras dessa geometria. Tornaram-se, assim, exemplos clássicos. Além desses, vamos apresentar também o próprio fractal construído por Mandelbrot em suas análises. As construções aqui apresentadas têm Barbosa (2005) e Janos (2008) como referências.

\subsection{1.}

\section{Conjunto de Cantor}

Georg Cantor (1845 - 1918) nasceu na Rússia, assumiu nacionalidade alemã e mudou-se para o país em 1856, onde seguiu com seus estudos. Sua graduação em matemática foi concluída na Universidade de Berlim, onde também concluiu seu doutorado em 1867, com uma tese sobre teoria dos números.

Lecionou nessa universidade e dentre os conteúdos aos quais se dedicou, destacam-se o conceito de infinito e o desenvolvimento da teoria dos conjuntos.

Segundo Barbosa (2005), a linguagem utilizada por Cantor em sua teoria era simplória e não era baseada em axiomas, o que a tornou mais fácil de ser compreendida, despertando a atenção e o desejo de outros estudiosos em formalizar e axiomatizar os conteúdos. Em 1908, o matemático e filósofo alemão Ernst Zermelo (1871 - 1953) iniciou esse desenvolvimento. Assim, indiretamente, Cantor possibilitou o advento de uma forma mais rigorosa e axiomática de enxergar a matemática, proporcionando a ela uma linguagem universal. 


\section{Figura 2 - Georg Cantor.}

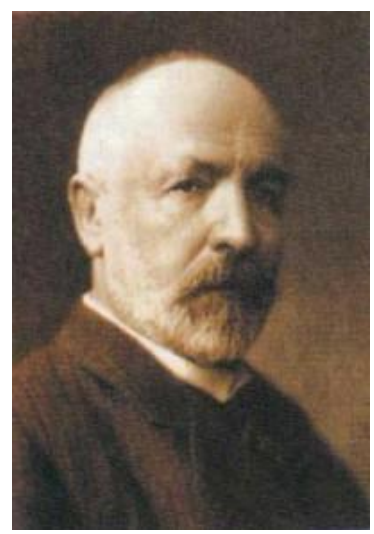

Fonte: www.storyofmathematics.com, acesso em 09 de março de 2017.

O Fractal atribuído a Cantor é chamado de "Conjunto de Cantor" ou "Poeira de Cantor". Sua ideia central é retirar infinitamente partes determinadas de um todo - o conjunto é caracterizado pelo que permanece após as retiradas.

Mais especificamente, a construção do Conjunto de Cantor é iniciada a partir do segmento de reta que representa o intervalo $[0,1]$, dividido em três partes iguais. Em seguida, o intervalo aberto do centro deve ser removido. Ao repetir o processo de divisão e exclusão quantas vezes forem desejadas, sempre restarão pedaços de segmentos com medida igual a um terço das medidas dos segmentos da etapa anterior. As sobras configuram o Conjunto de Cantor. A autossemelhança pode ser observada facilmente, pois se trata de um fractal simples, formado apenas por segmentos de reta.

Figura 3 - Conjunto de Cantor após 5 iterações.

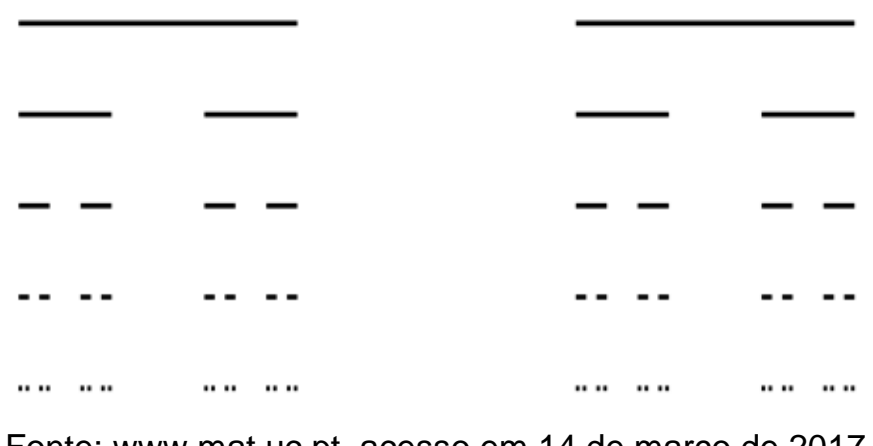

Fonte: www.mat.uc.pt, acesso em 14 de março de 2017. 


\subsection{2.}

\section{Fractais de Koch}

Helge Von Koch (1870 - 1924) nasceu na Suécia, onde completou seus estudos. Cursou matemática na Universidade de Estocolmo e também cumpriu seu doutorado lá, em 1892.

Após sua formação, lecionou na Universidade de Uppsala como professor adjunto, mas não conseguiu a vaga de titular. Diante dessa recusa, entrou para o departamento de matemática pura no Instituto Real de Tecnologia, em 1905. Poucos anos depois, em 1911, assumiu a cadeira de seu antigo professor Gösta Mittag-Leffler na Universidade de Estocolmo.

\section{Figura 4 - Helge Von Koch.}

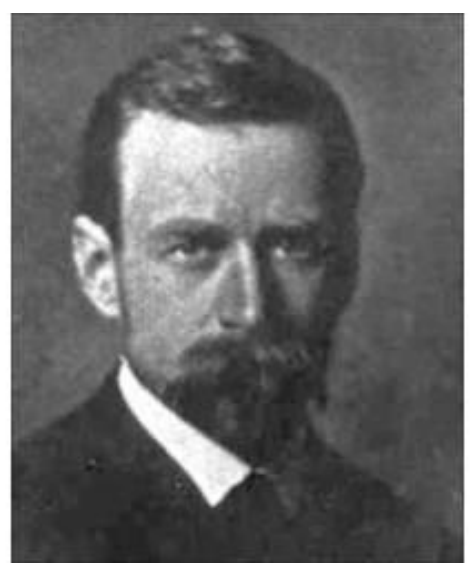

Fonte: timerime.com, acesso em 29 de março de 2017.

Os trabalhos de Koch, em sua maioria, versavam sobre determinantes infinitos e operadores lineares. Porém, foi ao estudar cálculo e curvas diferenciáveis que encontrou motivação para elaborar seu modelo fractal. Tentou construir uma curva contínua e não diferenciável, isto é, sem tangentes em seus pontos, e deu origem à Curva de Koch. ${ }^{1}$

Sua construção é feita a partir de um segmento de reta dividido em três partes iguais. Na parte central, deve ser construído um triângulo equilátero e retirado o intervalo aberto que representa sua base. $O$ processo deve ser repetido em todos os segmentos restantes quantas vezes forem necessárias. 
Se a estruturação da curva de Koch for iniciada sobre cada lado de um polígono regular, temos uma llha de Koch. A mais famosa é aquela obtida a partir do triângulo equilátero. Logo no início das repetições, começa a se assemelhar ao esboço de um floco de neve visto no microscópio. Justamente por isso, essa ilha de Koch recebe o nome especial de Floco de Neve.

Figura 5 - Construção da Curva de Koch e do Floco de Neve.
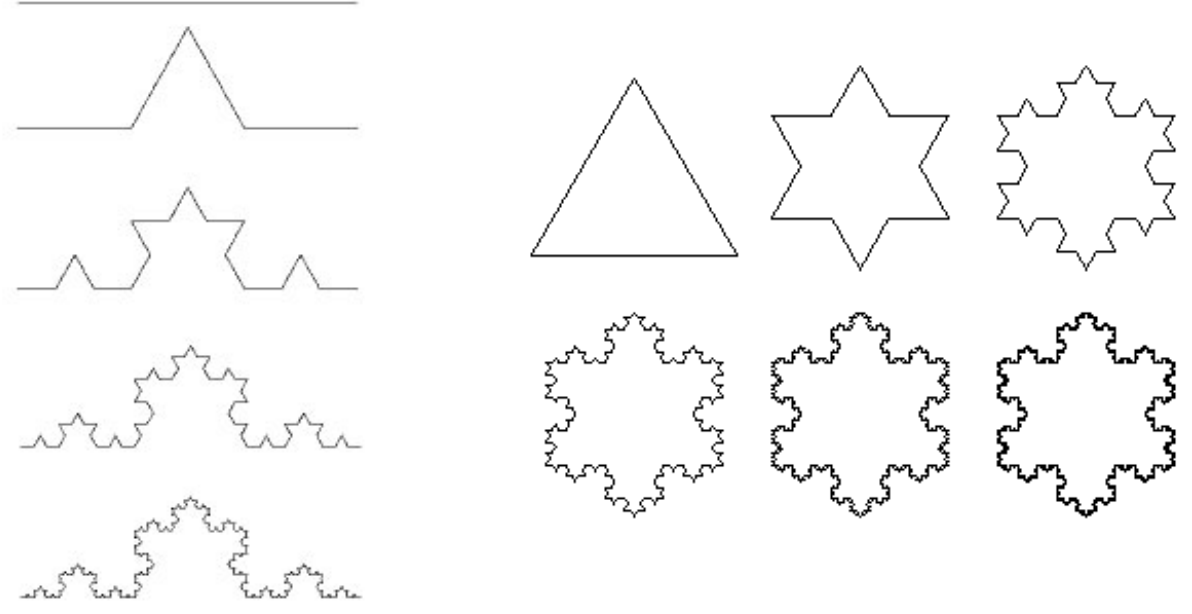

Fonte: www.hierophant.com.br, acesso em 03 de abril de 2017.

\subsection{3.}

\section{Fractais de Sierpinski e Menger}

Waclaw Sierpinski (1882 - 1969) nasceu na região que hoje é a Polônia, mas que pertencia ao Império Russo no século XIX. Graduou-se em matemática na Universidade de Varsóvia e completou seu doutorado na Universidade Jaguelônica, na cidade de Cracóvia, também na Polônia. Além disso, estudou filosofia e astronomia, ganhando tão grande prestígio nessa área, que uma das crateras lunares recebe seu nome. Em 1908, passou a lecionar na Universidade de Leópolis, Ucrânia.

Em 1914, Sierpinski se encontrava na Rússia, e a primeira guerra mundial estava iniciando. Havia perseguição aos poloneses e ele decide trabalhar em Moscou na tentativa de evitar confrontos. Quando a guerra acaba, Sierpinski volta a Leópolis, mas logo depois assume cargo na Universidade de Varsóvia, onde permanece lecionando. ${ }^{2}$

2 ENCYCLOPEDIA BRITANNICA, Waclaw Sierpinski. Disponível em: <global.britannica.com>. Acesso em 03 de abril de 2017. 
Figura 6 - Waclaw Sierpinski.

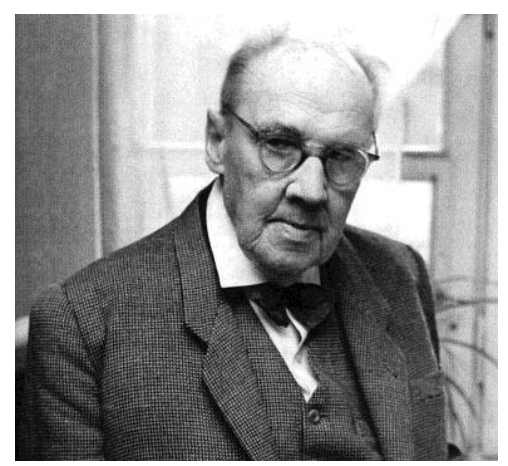

Fonte: alchetron.com, acesso em 04 de abril de 2017.

A construção do triângulo de Sierpinski é iniciada com um triângulo equilátero. Marcam-se os pontos médios dos lados. Esses pontos serão os vértices de um novo triângulo, de intervalo aberto, que deve ser retirado. A operação é repetida nos triângulos equiláteros restantes, infinitas vezes.

Figura 7 - Construção do Triângulo de Sierpinski.
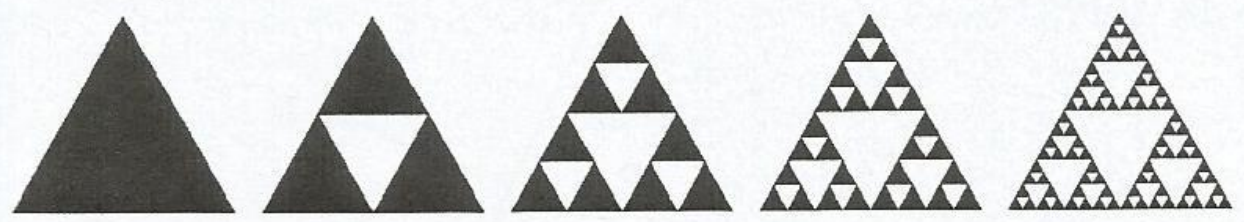

Fonte: JANOS, 2008.

Esse fractal tem diversas variações: a curva, a pirâmide e o tapete, todos de Sierpinski, e a esponja, de Menger, matemático austríaco. A diferença entre eles é a forma geométrica na qual sua construção é iniciada, contudo, a exclusão de algum elemento é o fato que todos têm em comum.

A curva de Sierpinski também se inicia em um triângulo equilátero, mas a retirada é de partes dos segmentos que formam os lados. Essas partes são encaixadas dentro da área do triângulo inicial, formando trapézios e, após muitas repetições, uma grande curva é revelada. 
Figura 8 - Construção da Curva de Sierpinski.

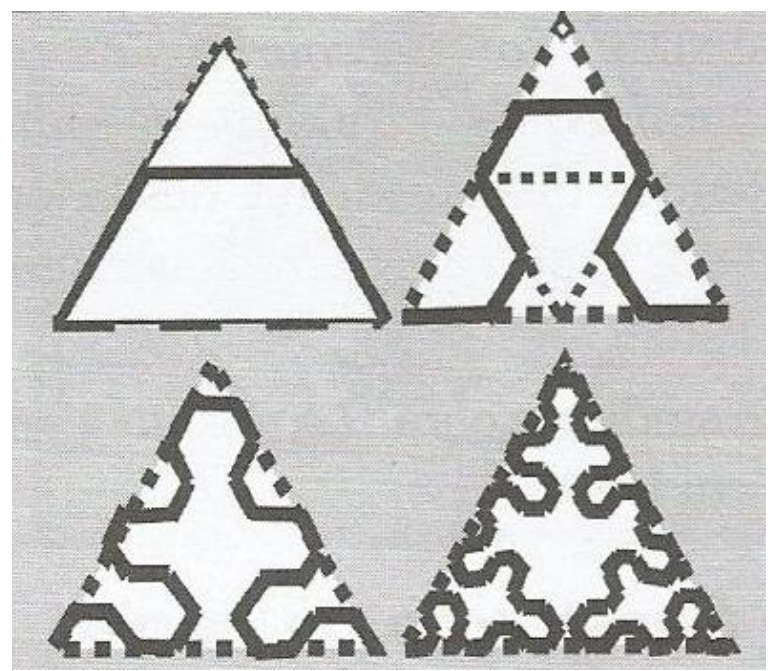

Fonte: BARBOSA, 2005

A pirâmide tem construção semelhante ao triângulo, porém em três dimensões.

Figura 9 - Pirâmide de Sierpinski.

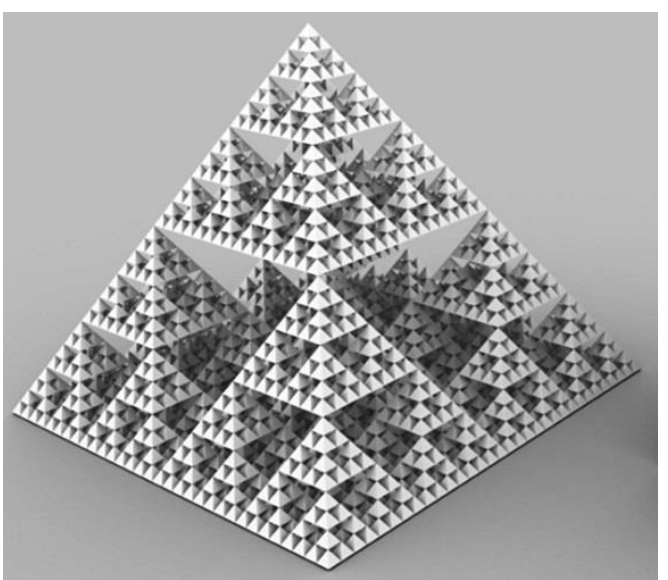

Fonte: www.comp.nus.edu.sg, acesso em 06 de abril de 2017.

O tapete é iniciado a partir de um quadrado dividido em nove quadrados congruentes. O quadrilátero aberto do centro deve ser retirado. 
Figura 10 - Construção do Tapete de Sierpinski.
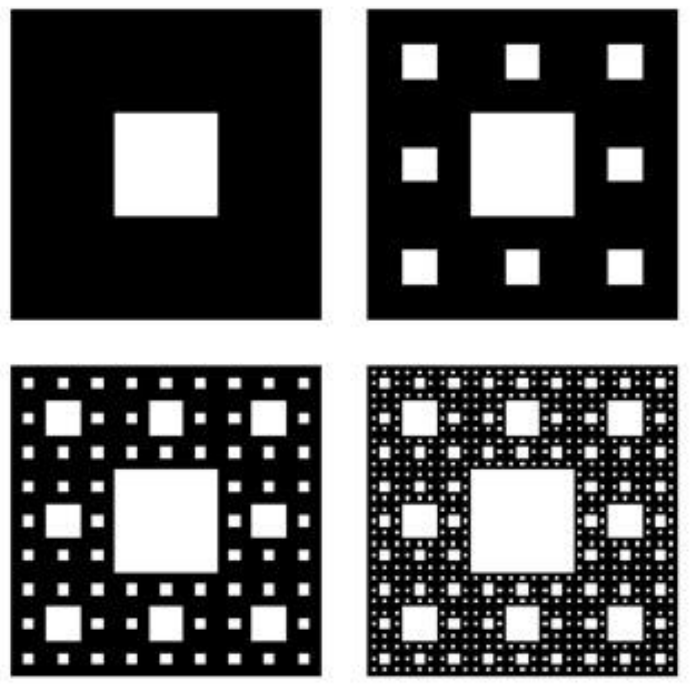

Fonte: professorandrios.blogspot.com.br, acesso em 06 de abril de 2017.

A esponja de Menger é a construção em três dimensões do tapete de Sierpinski.

Figura 11 - Construção da Esponja de Menger.

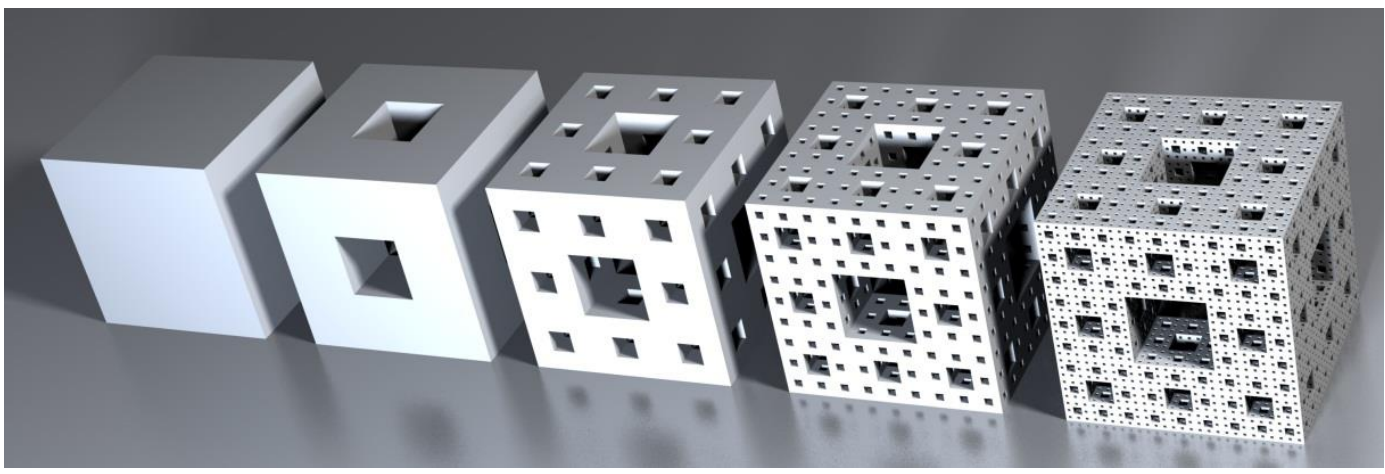

Fonte: www.epsilones.com, acesso em 08 de abril de 2017.

\subsection{4.}

\section{Fractal de Mandelbrot}

Benoit Mandelbrot (1924 - 2010) nasceu em Varsóvia, Polônia. Sua família era originalmente judaica e, com o advento da ameaça nazista no país, mudouse para Paris em 1936. 
Figura 12 - Benoit Mandelbrot.

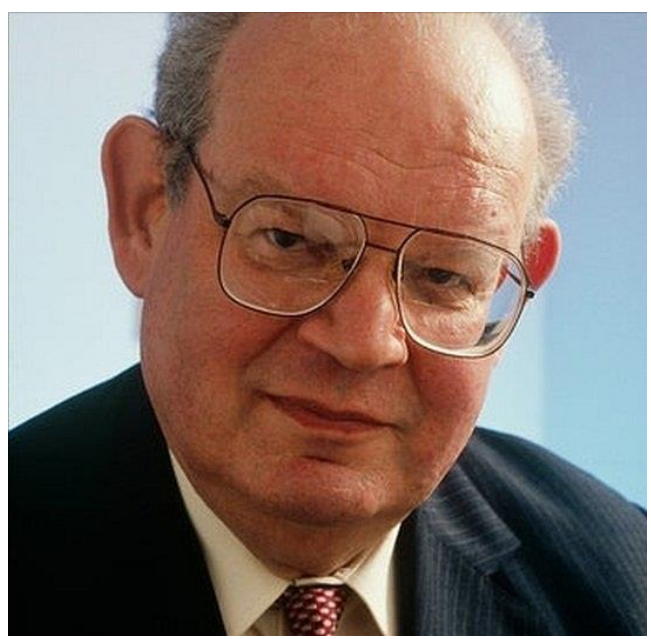

Fonte: alchetron.com, acesso em 21 de fevereiro de 2017.

$\mathrm{Na}$ universidade local, Szolem Mandelbrot, tio de Benoit, lecionava matemática. Ele fazia parte de um grupo denominado "Bourbaki", cujo objetivo era reconstruir a matemática francesa. Seus integrantes "visavam uma matemática formal e pura, sem influências possivelmente enganosas pelo visual geométrico." (BARBOSA, 2005, p.11).

No decorrer dos estudos de Benoit, ficava cada vez mais claro que a geometria era sua preferência. Ele era capaz de enxergar resoluções de diversos problemas através de conteúdos geométricos - justamente o pensamento a que o grupo Bourbaki era contrário.

Logo, por divergências de ideal, ele deixou a França em 1948 e foi estudar nos Estados Unidos, onde posteriormente se empregou na IBM e se deparou com os ruídos das linhas telefônicas já mencionados.

À procura de um padrão, Mandelbrot representou graficamente os erros de transmissão da telefonia. Percebeu que essas estruturas geométricas apresentadas se assemelhavam em qualquer escala de tempo: eram iguais para segundos, horas ou dias, por exemplo (figura 13). Mais precisamente, eram autossemelhantes. 
Figura 13 - Reprodução dos erros de transmissão da IBM.

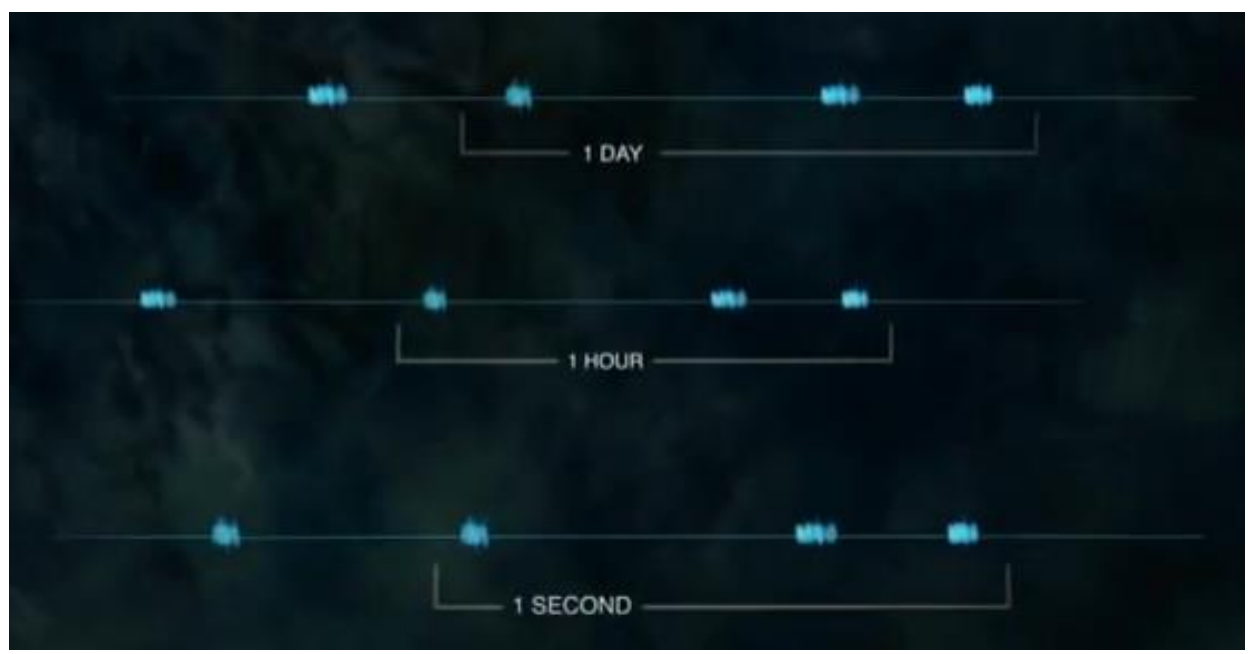

Fonte: www.youtube.com/watch?v=2M6CE1AcjFA, acesso em 10 de abril de 2017.

Considerou os ruídos das linhas telefônicas como um conjunto de Cantor, pois a imagem construída por ele era muito similar ao trabalho do matemático alemão. Assim como sempre haverá segmentos restantes na construção do conjunto de Cantor, Benoit concluiu que, infelizmente, pela maneira como a central telefônica estava constituída, sempre haveria ruídos na transmissão. Sugeriu, então, que a empresa aceitasse a existência dos erros e trabalhasse com um novo sistema que disponibilizasse um segundo recurso caso ocorresse erro no principal. Esse sistema atualmente é chamado de sistema de redundância, ainda presente na IBM nos dias atuais. ${ }^{3}$

Com o problema surgido na IBM, Mandelbrot começa a perceber a existência de fractais e intensifica seus estudos, além de construir o seu próprio fractal.

O fractal conhecido por seu nome é formado pelas seguintes equações recorrentes:

$$
\left\{\begin{array}{c}
x_{n+1}=x_{n}^{2}-y_{n}^{2}+a \\
y_{n+1}=2 x_{n} y_{n}+b
\end{array}\right.
$$

Tomamos como valores iniciais $\mathrm{x}_{0}=0$ e $\mathrm{y}_{0}=0$. As variáveis $a$ e $b$ são escolhidas aleatoriamente no universo dos números reais. 
Para a construção do chamado "Conjunto de Mandelbrot", um círculo de raio 2 deve ser desenhado com centro na origem do plano cartesiano. Calculamse os pontos $\left(x_{n}, y_{n}\right)$ utilizando as equações. Se o ponto permanecer dentro do círculo, deve ser pintado de preto. Se não permanecer, deve ser descartado.

Após a quantidade de iterações desejadas, novos valores de $a$ e $b$ devem ser escolhidos, e toda a construção se reinicia. Os Fractais de Mandelbrot são as diversas imagens formadas nas fronteiras do conjunto dos pontos pintados de preto, após o número desejado de escolhas para $a$ e $b$. Na figura 14 , temos a construção feita por Mandelbrot em uma e cinco iterações. Na figura 15, após 100 iterações.

Figura 14 - Primeiras iterações de Mandelbrot.
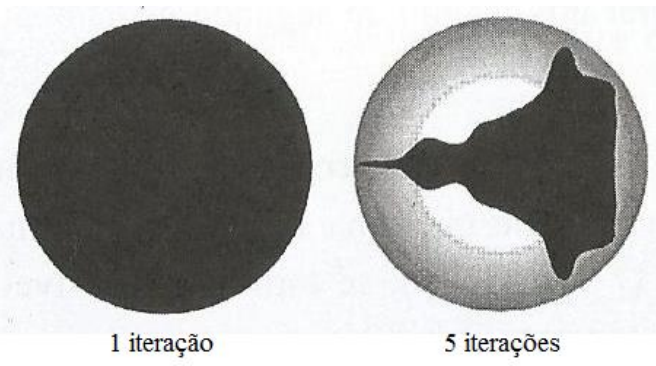

Fonte: JANOS, 2008

Figura 15 - Conjunto e fractais de Mandelbrot.
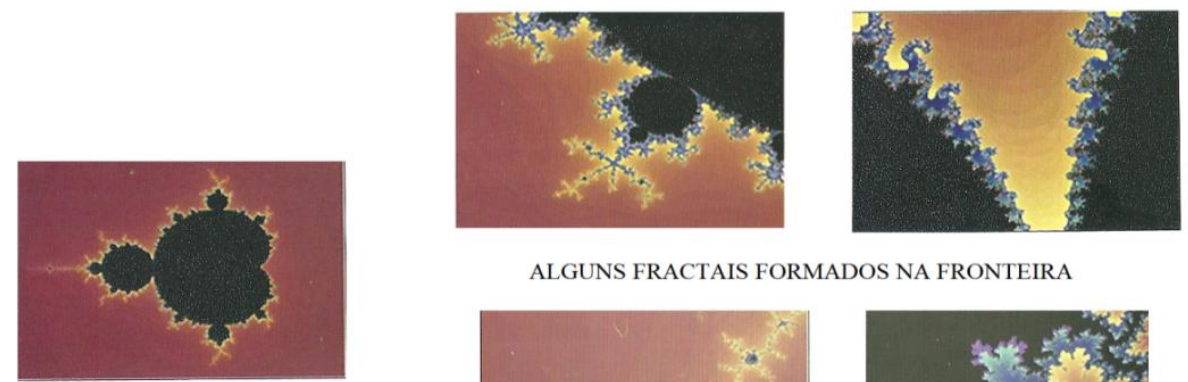

ALGUNS FRACTAIS FORMADOS NA FRONTEIRA
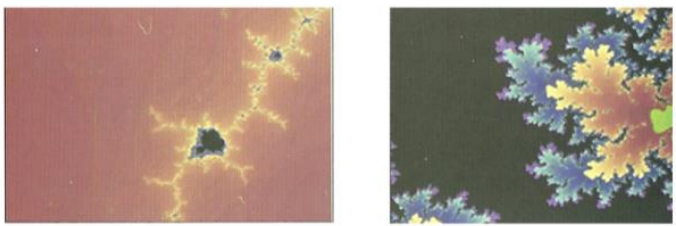

Fonte: JANOS, 2008. Composição própria. 
Segundo Barbosa (2005), a nova visualização geométrica estabelecida por Mandelbrot através dos fractais permitiu que cientistas das mais diversas áreas pudessem reformular, com enfoque mais propício, antigos problemas sem solução, como uma melhor representação geométrica da natureza, por exemplo. Além disso:
A Geometria dos Fractais está intimamente ligada à uma ciência chamada CAOS. As estruturas fragmentadas, extremamente belas e complexas dessa geometria, fornecem uma certa ordem ao Caos, razão de ser, às vezes, considerada como sua linguagem, que busca padrões dentro de um sistema por vezes aparentemente aleatório. (BARBOSA, 2005, p. 9).

Os fractais também têm sua influência nas artes, devido a seu apelo visual, e na cartografia, pois podem representar mais fielmente os relevos e formações da natureza ao se construírem mapas ou maquetes. Além disso, é possível estudar diversos conceitos matemáticos, inclusive na educação básica, através deles. No próximo capítulo, apresentaremos alguns exemplos. 


\section{3 \\ Seleção de conceitos matemáticos}

Em um fractal podemos identificar diversos conteúdos matemáticos adequados a diferentes níveis de escolaridade - seja visualmente com as formas geométricas, ou na sua construção, com cálculos e resoluções de equações, por exemplo. Também é possível utilizar a imagem de um fractal pronto para motivar o estudo de outros temas, tais como: divisões, progressões e cálculo de áreas.

Nesta seção, selecionamos alguns conteúdos matemáticos que podem ser explorados por professores da educação básica através da beleza dos fractais. É incontestável que muitos outros temas aqui não descritos também se conectam a essa geometria, mas optamos por apresentar aqueles que têm alguma conexão com as atividades propostas no próximo capítulo.

\section{1. \\ Perímetro e área de polígonos e circunferência}

Normalmente definimos perímetro como a soma dos comprimentos dos lados de uma figura. É importante salientar que essa definição só se aplica aos polígonos, pois "lado" é um elemento pertinente a eles. Se queremos calcular o perímetro de uma circunferência ou qualquer figura curva, não há como utilizar essa explicação. Portanto, a definição mais genérica que podemos dar é que se trata da medida do contorno de uma figura.

Já a área de uma figura é a porção do plano ocupada por ela (LIMA et al., 2005). A maneira mais comum de trabalhar áreas de polígonos no ensino fundamental é a aplicação direta ou contextualizada das fórmulas dos polígonos básicos (triângulos e quadriláteros convexos). Outro modo é desenhar os polígonos em malha quadriculada e, a partir da área de um pequeno quadrado, contar a quantidade total existente na parte interna do desenho.

Além disso, também podemos calcular a área de polígonos simples, construídos em uma malha de pontos, através da fórmula $S=\frac{1}{2} B+I-1$, que constitui o Teorema de Pick. Onde $B$ é a quantidade de pontos sobre as arestas e $I$, no interior do polígono. 
A abordagem a seguir mostra a dedução de fórmulas de área de alguns polígonos e da circunferência utilizando imagens, o que seria possível e interessante de ser feito em sala de aula. Também vamos explicitar seus perímetros $(2 \mathrm{p})$.

Iniciaremos com as áreas do quadrado e do retângulo, que são calculadas tomando como unidade um quadrado de lado unitário. Ao contarmos quantas vezes esse quadrado está contido no polígono, encontraremos a medida da área. Caso as medidas do polígono não sejam inteiras, podemos dividir a unidade de área em quadrados menores, todos de mesma medida, de maneira que se encaixem na figura dada. Para utilizarmos esse método, é necessário que os segmentos que formam os lados dos polígonos sejam comensuráveis. As áreas dos outros polígonos que serão citados são provenientes destas duas.

\section{a) Quadrado}

Em um quadrado de lado $l$, a unidade de área citada, aparece $l$ vezes em $l$ linhas.

Portanto, sua área é dada por:

$$
S=l . l \rightarrow S=l^{2}
$$

Figura 16 - Quadrado dividido em unidades de área.

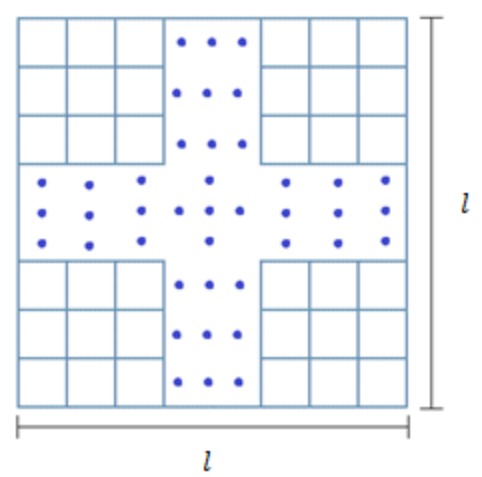

Fonte: Elaboração própria.

Ao calcular o perímetro do quadrado, temos: $2 p=l+l+l+l=4 l$. 
b) Retângulo

O raciocínio do cálculo da área do retângulo é análogo ao do quadrado. Se temos um retângulo de lados $a$ e $b$, a unidade de área aparecerá $a$ vezes em $b$ linhas.

Assim, a área do retângulo é dada por:

$$
S=a \cdot b
$$

Figura 17 - Retângulo dividido em unidades de área.

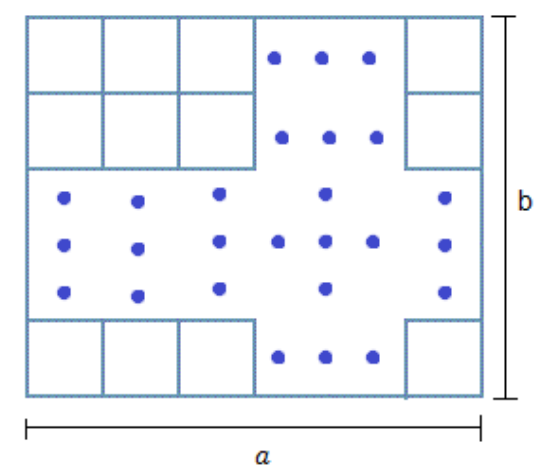

Fonte: Elaboração própria

Ao calcular o perímetro do retângulo, temos: $2 p=a+b+a+b=2 a+2 b$.

\section{c) Paralelogramo}

Todo paralelogramo pode ser construído de maneira que esteja contido em um retângulo, que tomaremos como base para o cálculo da área. Seja um paralelogramo de base $a$, contido em um retângulo de base $a+x$ e altura $h$, conforme a figura 18. Ao juntar as partes que não compõem o paralelogramo, formamos um pequeno retângulo de medidas $x \mathrm{e} h$. Logo, a área do paralelogramo será dada por:

$$
\begin{gathered}
S=(a+x) \cdot h-x \cdot h \\
\therefore \quad S=(a+x-x) \cdot h \\
\therefore \quad S=a \cdot h
\end{gathered}
$$


Figura 18 - Paralelogramo contido no retângulo.

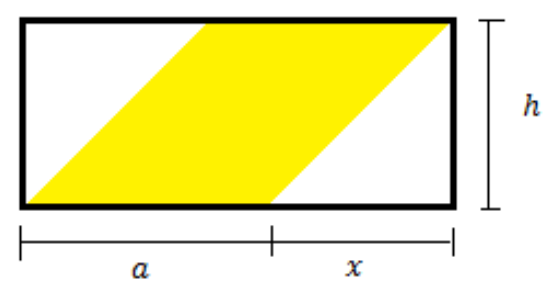

Fonte: Elaboração própria

Para calcular o perímetro do paralelogramo, necessitamos da medida de um dos lados, não explicitada na figura 18 - vamos chamar de c. Logo, o perímetro do paralelogramo é dado por: $2 p=a+c+a+c=2 a+2 c$.

Podemos deixar o lado $c$ em função das medidas da figura, através do Teorema de Pitágoras:

$$
\begin{aligned}
c^{2} & =x^{2}+h^{2} \\
\therefore \quad c & =\sqrt{x^{2}+h^{2}}
\end{aligned}
$$

Dado isso, nessas condições, o perímetro do paralelogramo é dado por:

$$
2 p=2 a+2 \sqrt{x^{2}+h^{2}}
$$

d) Triângulo

Ao traçarmos uma diagonal em um paralelogramo de base $a$ e altura $h$, construímos dois triângulos de mesma base e altura, o que nos mostra que a área de um triângulo é metade da área do paralelogramo.

Temos assim:

$$
S=\frac{a \cdot h}{2}
$$

Figura 19 - Triângulo contido no paralelogramo.

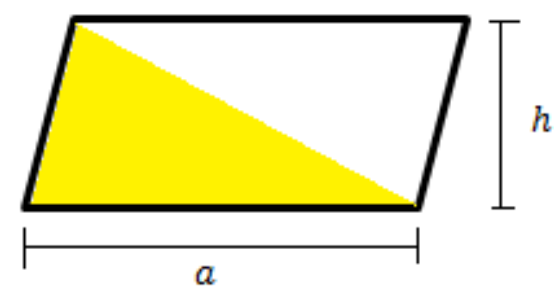

Fonte: Elaboração própria 
Para calcular o perímetro do triângulo, necessitamos das medidas dos outros lados que não foram explicitadas na figura 19. Vamos chamar de $b, c$, conforme a figura 20. Logo, o perímetro do triângulo é dado por: $2 p=a+b+c$.

Figura 20 - Triângulo com medidas dos lados.

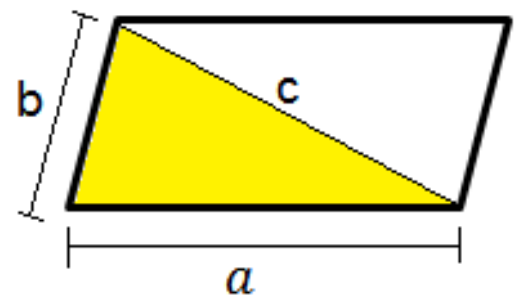

Fonte: Elaboração própria

e) Trapézio

Se unirmos um paralelogramo de base $b$ e altura $h$ com um triângulo de mesma altura e base $a-b$ como mostra a figura 21 , teremos um trapézio de bases $a$ e $b$ e altura $h$. Logo, a área do trapézio será:

$$
\begin{aligned}
& S=b \cdot h+\frac{(a-b) \cdot h}{2} \\
& \therefore \quad S=\frac{2 b h+a h-b h}{2}
\end{aligned}
$$

$$
\therefore \quad S=\frac{b h+a h}{2}
$$

$$
\therefore \quad S=\frac{(b+a) \cdot h}{2}
$$


Figura 21 - Trapézio formado por paralelogramo e triângulo.

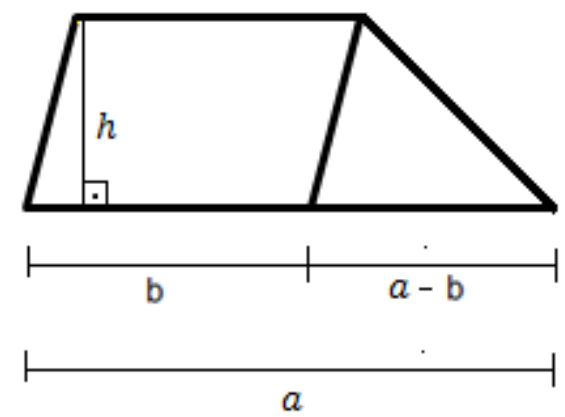

Fonte: Elaboração própria

Para calcular o perímetro do trapézio, necessitamos das medidas dos outros lados que não foram explicitadas na figura 21. Vamos chamar de $c, d$, conforme a figura 22. Logo, o perímetro do triângulo é dado por:

$$
2 p=a+b+c+d .
$$

Figura 22 - Trapézio com medidas dos lados.

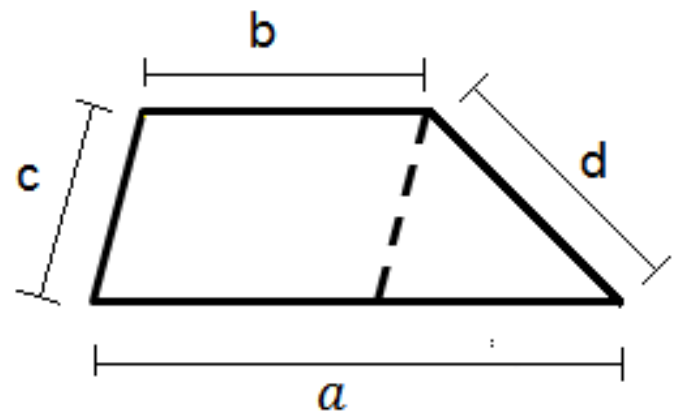

Fonte: Elaboração própria

f) Circunferência

PROPRIEDADE 1: a medida do contorno de uma circunferência é dada por $2 \pi r$.

DEMONSTRAÇÃO: 
Por definição, temos que a constante $\pi$ é a medida da razão entre o comprimento $(\mathrm{C})$ e o diâmetro (D) de uma circunferência. Sabemos também que o diâmetro é o dobro do raio $(r)$. Logo:

$$
\begin{aligned}
& \frac{C}{D}=\pi \\
& \therefore \quad C=\pi \cdot D \\
& \therefore \quad C=\pi \cdot(2 r) \\
& \therefore \quad C=2 \pi r
\end{aligned}
$$

PROPRIEDADE 2: a área de uma circunferência é dada por $\pi r^{2}$.

\section{DEMONSTRAÇÃO:}

Seja um polígono regular de $\mathrm{n}$ lados, inscrito em uma circunferência de raio $r$. Vamos dividir esse polígono em triângulos isósceles iguais, com vértice no centro da circunferência e dois lados de medida $r$. Vamos chamar a base de $b$, que também é lado do polígono, e a altura relativa a $b$, de $h$. Os elementos citados podem ser observados no exemplo da figura 23.

Figura 23 - Circunferência com dodecágono inscrito.

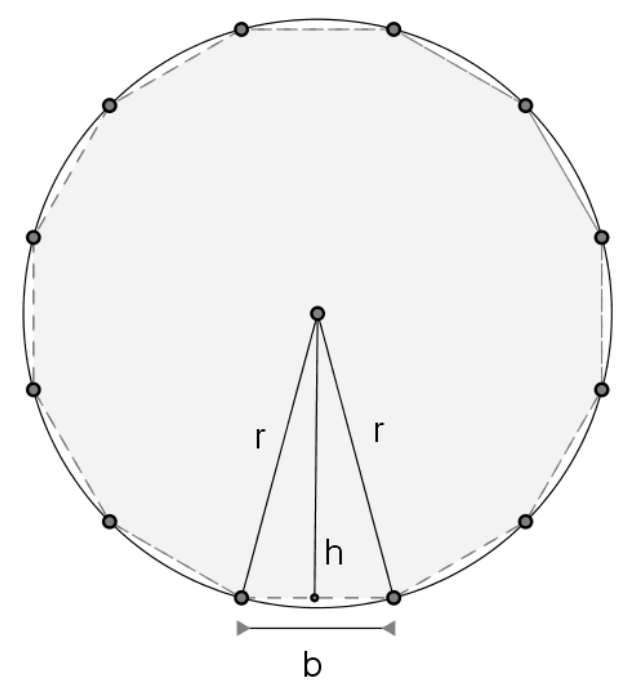

Fonte: Elaboração própria 
Como o polígono de $\mathrm{n}$ lados é regular, sua área $\left(\mathrm{S}_{\mathrm{n}}\right)$ será $n \cdot \frac{b \cdot h}{2}$.

Temos que o perímetro do polígono $\left(P_{n}\right)$ é dado por $n b$.

Logo: $S_{n}=\frac{P_{n} \cdot h}{2}$.

Quando $n \rightarrow \infty$, temos $P_{n} \rightarrow$ comprimento da circunferência e $\mathrm{h} \rightarrow r$.

Portanto:

$$
\begin{aligned}
& S=\frac{2 \pi r \cdot r}{2} \\
\therefore \quad & S=\pi r^{2}
\end{aligned}
$$

\section{2. \\ Área e volume de blocos retangulares}

Fractais também podem ser formados por figuras tridimensionais. Nesta seção, escolhemos analisar os chamados blocos retangulares. A área de um bloco retangular é formada pela área dos retângulos que compõem suas faces. Já o volume é o espaço total ocupado por ele e pode ser deduzido de maneira análoga a que fizemos na área do retângulo. Agora, tomamos como unidade de volume um cubo menor de arestas unitárias: ao contarmos quantas vezes esse cubo unitário está contido no paralelepípedo, teremos a medida do volume. Em um paralelepípedo de dimensões $a, b, c$, a unidade de volume citada aparece $a$ vezes em $b$ linhas e em $c$ colunas.

Figura 24 - Bloco retangular dividido em unidades de volume.

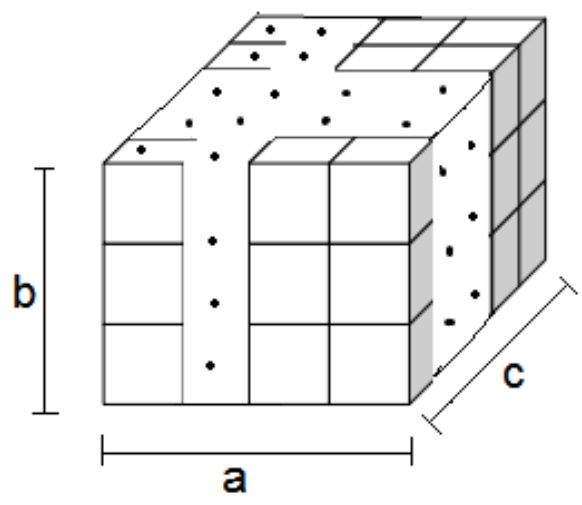

Fonte: Elaboração própria.

Portanto, seu volume é dado por: $\quad V=a . b . c$ 
Podemos verificar, também, que o bloco é formado por três pares de faces retangulares. Cada par possui as seguintes dimensões: $a \times b, a \times c, b \times c$. Portanto, a área do sólido é dada por: $S=2 a b+2 a c+2 b c$.

Para o caso particular em que $a=b=c$, temos um cubo. O cubo unitário que representa a unidade de volume aparece $a$ vezes em $a$ linhas e em $a$ colunas.

Figura 25 - Cubo dividido em unidades de volume.

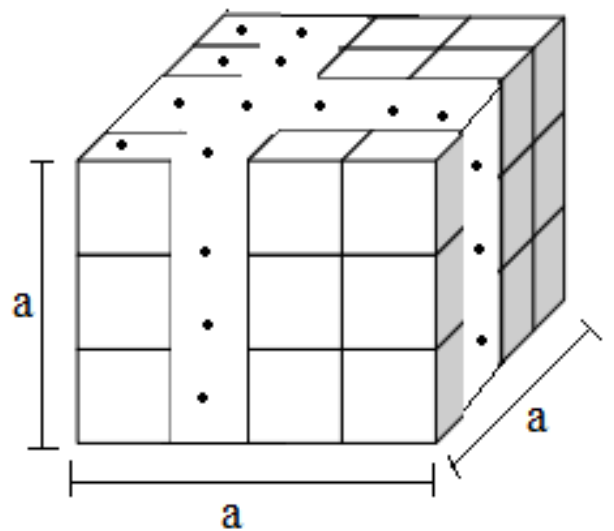

Fonte: Elaboração própria.

Portanto, o volume do cubo é dado por: $V=a \cdot a \cdot a=a^{3}$.

Para sua área, temos: $S=2 a a+2 a a+2 a a=6 a^{2}$.

\section{3.}

\section{Progressões}

Progressão aritmética (PA) é uma sequência numérica na qual cada termo é obtido através da soma do anterior com uma constante. Essa constante é chamada de razão da PA e usualmente representada pela letra r. (IEZZI et al., 2010).

Seguem alguns exemplos:

(i) $(2,4,6,8, \ldots)$ PA crescente de razão 2 .

(ii) $(-1,-2,-3,-4, \ldots)$ PA decrescente de razão -1 .

(iii) $(8,8,8,8, \ldots)$ PA constante de razão 0 . 
Notemos que, se temos o primeiro termo de uma progressão aritmética, ao somá-lo com a razão, obtemos o segundo. Para obtermos o terceiro termo, somamos duas vezes a razão ao primeiro e assim sucessivamente. Seguindo esse raciocínio, se quisermos obter o enésimo termo $\left(a_{n}\right)$, somamos $(n-1)$ vezes a razão ao primeiro termo $\left(a_{1}\right)$. Ou seja: $a_{n}=a_{1}+(n-1) \cdot r$, que constitui a fórmula do termo geral de uma progressão aritmética.

PROPRIEDADE 3: a fórmula da soma dos $\mathrm{n}$ primeiros termos de uma progressão aritmética é dada por: $S_{n}=\frac{\left(a_{1}+a_{n}\right) \cdot n}{2}$.

\section{DEMONSTRAÇÃO:}

Se a PA é da forma $\left(a_{1}, a_{2}, a_{3}, \ldots\right)$, a soma dos $n$ primeiros termos será:

$$
S_{n}=a_{1}+a_{2}+a_{3}+\cdots+a_{n-1}+a_{n}
$$

Escrevendo de trás para frente, temos:

$$
S_{n}=a_{n}+a_{n-1}+a_{n-2}+\cdots+a_{2}+a_{1}
$$

Somando as equações:

$2 S_{n}=\left(a_{1}+a_{n}\right)+\left(a_{2}+a_{n-1}\right)+\left(a_{3}+a_{n-2}\right)+\cdots+\left(a_{n-1}+a_{2}\right)+\left(a_{n}+a_{1}\right)$

Pela fórmula do termo geral, temos que:

$$
\begin{gathered}
a_{2}=a_{1}+r \\
a_{3}=a_{1}+2 r \\
\vdots \\
a_{n-2}=a_{1}+(n-3) r \\
a_{n-1}=a_{1}+(n-2) r
\end{gathered}
$$

Substituindo em $(*)$ :

$$
\begin{gathered}
2 S_{n}=\left(a_{1}+a_{n}\right)+\left(a_{1}+r+a_{1}+(n-2) r\right)+\left(a_{1}+2 r+a_{1}+(n-3) r\right)+\cdots \\
+\left(a_{1}+(n-2) r+a_{1}+r\right)+\left(a_{n}+a_{1}\right)
\end{gathered}
$$




$$
\begin{gathered}
\therefore \quad 2 S_{n}=\left(a_{1}+a_{n}\right)+\left(a_{1}+a_{1}+(1+n-2) r\right)+\left(a_{1}+a_{1}+(2+n-3) r\right)+\cdots \\
+\left(a_{1}+a_{1}+(n-2+1) r\right)+\left(a_{n}+a_{1}\right) \\
\therefore \quad 2 S_{n}=\left(a_{1}+a_{n}\right)+\left(a_{1}+a_{1}+(n-1) r\right)+\left(a_{1}+a_{1}+(n-1) r\right)+\cdots \\
+\left(a_{1}+a_{1}(n-1) r\right)+\left(a_{n}+a_{1}\right)
\end{gathered}
$$

Como $a_{1}+(n-1) r=a_{n}$, temos:

$$
\begin{gathered}
2 S_{n}=\left(a_{1}+a_{n}\right)+\left(a_{1}+a_{n}\right)+\left(a_{1}+a_{n}\right)+\cdots+\left(a_{1}+a_{n}\right)+\left(a_{n}+a_{1}\right) \\
\therefore \quad 2 S_{n}=\left(a_{1}+a_{n}\right) \cdot n \\
\therefore \quad S_{n}=\frac{\left(a_{1}+a_{n}\right) \cdot n}{2}
\end{gathered}
$$

Podemos caracterizar as fórmulas do termo geral e da soma dos termos de progressões aritméticas como funções. Vamos desenvolver essa abordagem não usual na educação básica.

Sabemos que o termo geral de uma progressão aritmética é dado por $a_{n}=a_{1}+(n-1) \cdot r$. Arrumando convenientemente, temos $a_{n}=r n+\left(a_{1}-r\right)$.

Se $r=0$, temos $a_{n}=a_{1}$, o que define uma função constante e uma progressão aritmética estacionária.

Se $r \neq 0$, temos que $a_{n}$ é definido por um polinômio de grau um, caracterizando uma função de $1^{\circ}$ grau em $n \in N$. Comparando com o formato tradicional da função afim, ou seja, $y=a x+b$, temos:

$$
\left\{\begin{array}{l}
y=a_{n} \\
x=n \\
a=r \\
b=a_{1}-r
\end{array}\right.
$$

Se $r>0$, a PA será crescente. Se $r<0$, a PA será decrescente.

A figura 26 apresenta opções para o gráfico da função que representa 0 termo geral de uma progressão aritmética, com $a_{n}>0$. 
Figura 26 - Gráficos da função que representa o termo geral de uma PA.
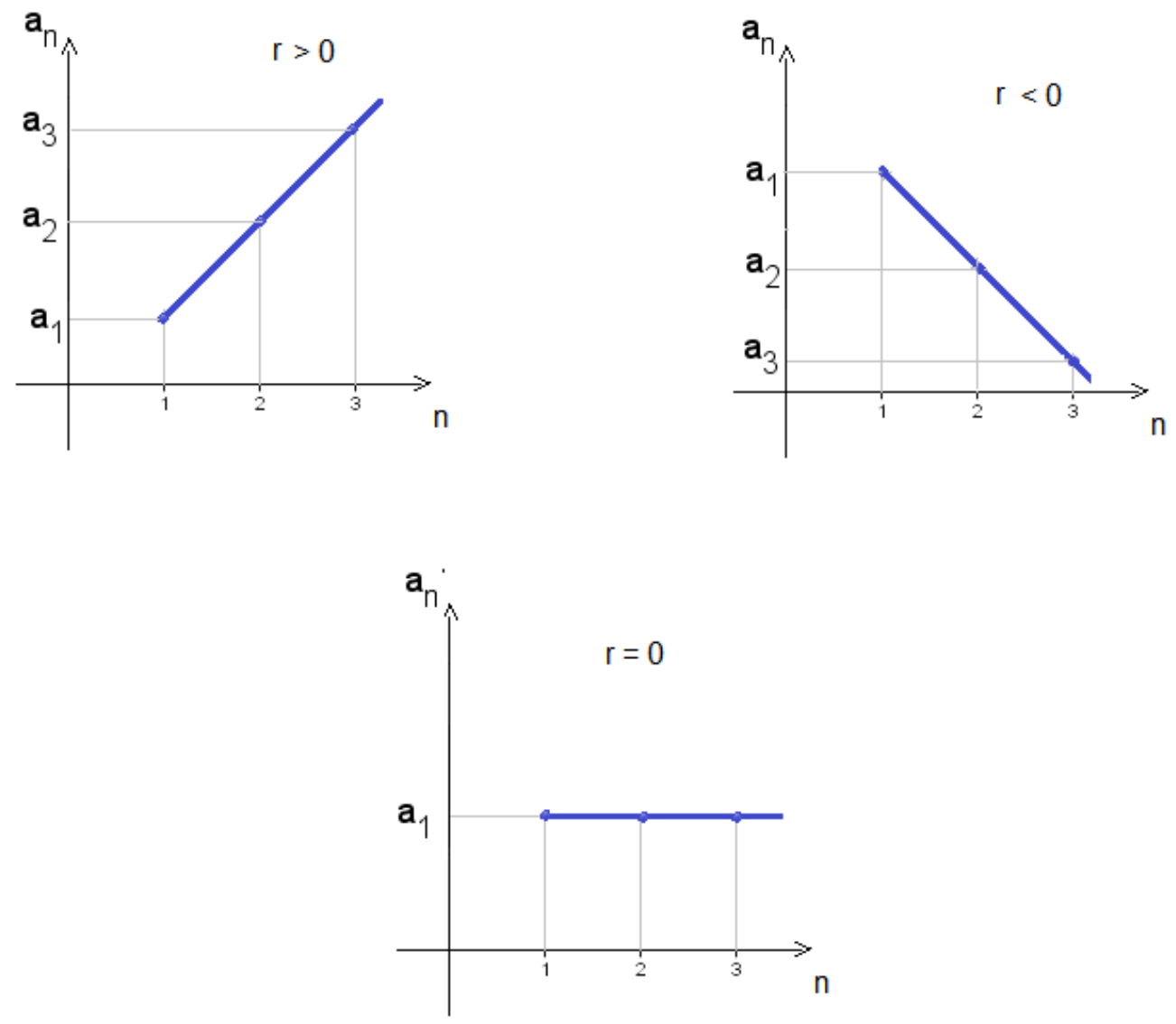

Fonte: Elaboração própria

Já a fórmula da soma dos termos de uma progressão aritmética que é dada por $S_{n}=\frac{\left(a_{1}+a_{n}\right) \cdot n}{2}$, se arrumada convenientemente, nos mostra que $S_{n}=\frac{r}{2} n^{2}+\left(a_{1}-\frac{r}{2}\right) n$.

Se $r=0$, temos $S_{n}=a_{1} n$, o que define uma função constante caso $a_{1}=0$ ou do $1^{\circ}$ grau em $n \in N$ caso $a_{1} \neq 0$.

Se $a_{1}>0$, o gráfico é crescente. Se $a_{1}<0$, o gráfico é decrescente.

Se $r \neq 0$, temos que $S_{n}$ é definido por um polinômio de grau dois em $n \in$ $N$, caracterizando uma função de $2^{\circ}$ grau. Comparando com 0 formato tradicional da função quadrática, ou seja, $y=a x^{2}+b x+c$, temos:

$$
\left\{\begin{array}{l}
y=S_{n} \\
x=n \\
a=\frac{r}{2} \\
b=a_{1}-\frac{r}{2} \\
c=0
\end{array}\right.
$$


Se $r>0$, o gráfico será crescente. Se $r<0$, o gráfico será decrescente.

A figura 27 apresenta opções para o gráfico da função que representa a soma dos termos de uma progressão aritmética, com $S_{n}>0$.

Figura 27 - Gráficos da função que representa a soma dos termos da PA.
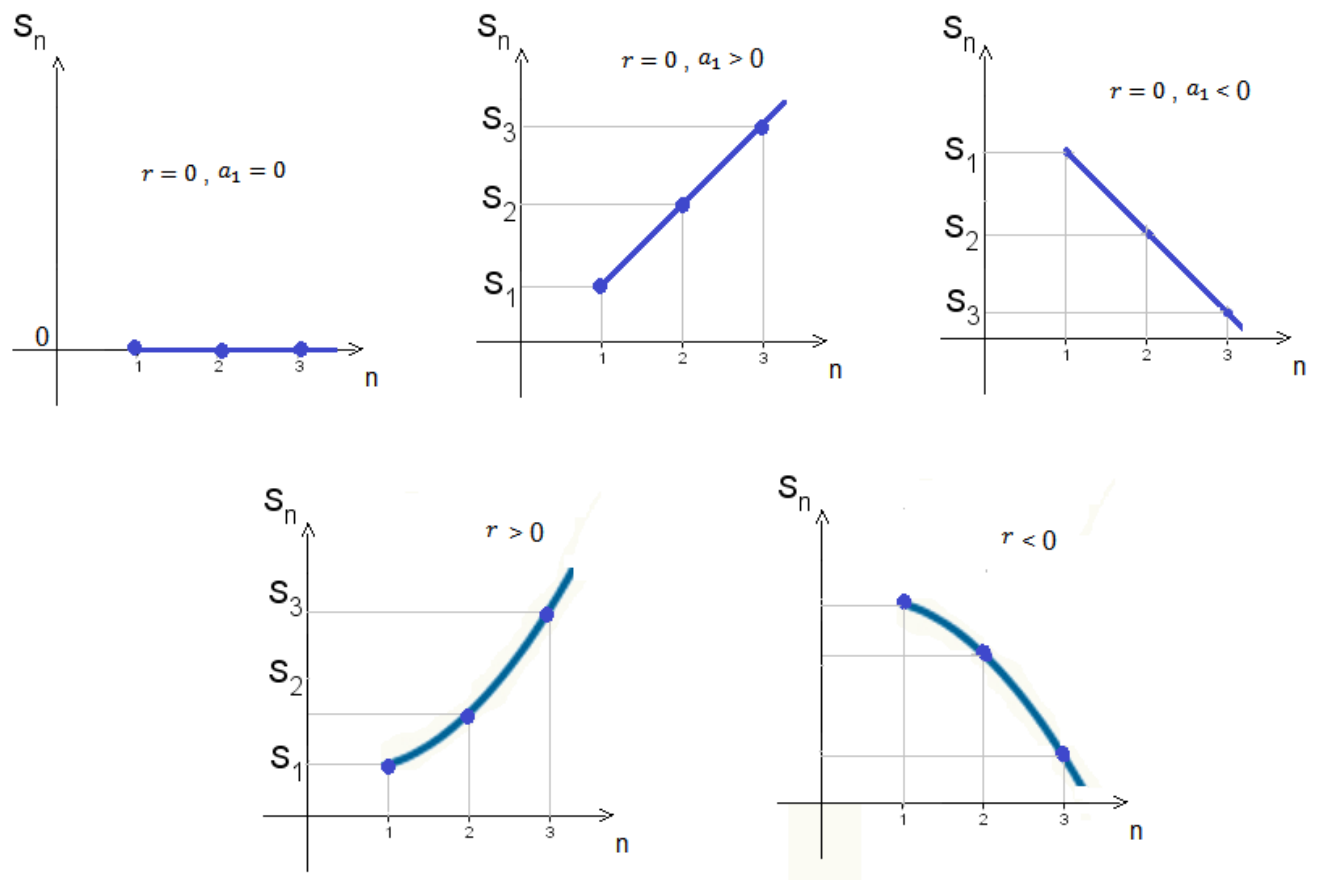

Fonte: Elaboração própria

Outra progressão conhecida é a geométrica. Progressão geométrica (PG) é uma sequência numérica na qual cada termo é obtido através do produto do anterior por uma constante. Essa constante é chamada de razão da PG e usualmente representada pela letra q. (IEZZI et al., 2010).

Seguem alguns exemplos:

(i) $(2,4,8,16, \ldots)$ PG crescente de razão 2.

(ii) $(-1,-3,-9,-27, \ldots)$ PG decrescente de razão 3 .

(iii) $(8,8,8,8, \ldots)$ PG constante de razão 1 .

(iv) $\left(2,-1, \frac{1}{2}, \frac{-1}{4}, \ldots\right) \mathrm{PG}$ oscilante de razão $\frac{-1}{2}$.

Notemos que, se temos o primeiro termo de uma progressão geométrica, ao multiplicá-lo pela razão, obtemos o segundo. Para obtermos o terceiro termo, multiplicamos a razão ao quadrado pelo primeiro, e assim sucessivamente. 
Seguindo esse raciocínio, se quisermos obter o enésimo termo $\left(a_{n}\right)$, elevamos a razão a $(\mathrm{n}-1)$ e multiplicamos pelo primeiro termo $\left(a_{1}\right)$. Ou seja: $a_{n}=a_{1} \cdot q^{n-1}$, que constitui a fórmula do termo geral de uma progressão geométrica.

PROPRIEDADE 4: a fórmula da soma dos $\mathrm{n}$ primeiros termos de uma progressão geométrica é dada por: $S_{n}=a_{1} \cdot \frac{1-q^{n}}{1-q}$.

DEMONSTRAÇÃO:

Se a PG é da forma $\left(a_{1}, a_{2}, a_{3}, \ldots\right)$, a soma dos $n$ primeiros termos será:

$$
S_{n}=a_{1}+a_{2}+a_{3}+\cdots+a_{n-1}+a_{n}
$$

Multiplicando por q, temos:

$$
q S_{n}=a_{1} q+a_{2} q+a_{3} q+\cdots+a_{n-1} q+a_{n} q
$$

Pela definição de progressão geométrica:

$$
q S_{n}=a_{2}+a_{3}+a_{4}+\cdots+a_{n}+a_{n+1}
$$

Subtraindo de $(*)$ :

$$
\begin{gathered}
S_{n}-q S_{n}=a_{1}-a_{n+1} \\
\therefore \quad(1-q) S_{n}=a_{1}-a_{n+1} \\
\therefore \quad S_{n}=\frac{a_{1}-a_{n+1}}{1-q}
\end{gathered}
$$

Pela fórmula do termo geral, temos que: $a_{n+1}=a_{1} \cdot q^{n}$, logo:

$$
\begin{aligned}
S_{n}= & \frac{a_{1}-a_{1} \cdot q^{n}}{1-q} \\
\therefore \quad S_{n} & =\frac{a_{1} \cdot\left(1-q^{n}\right)}{1-q}
\end{aligned}
$$




$$
\therefore \quad S_{n}=a_{1} \cdot \frac{1-q^{n}}{1-q}
$$

Na educação básica, a caracterização das progressões geométricas como função é mais comum do que nas progressões aritméticas. Talvez isso se estabeleça pelo fato de a fórmula do termo geral de uma PG $\left(a_{n}=a_{1} \cdot q^{n-1}\right)$, já estar no formato de função exponencial. Inclusive, muitos problemas trabalhados no ensino médio são contextualizados dessa forma.

A figura 28 exibe opções para o gráfico da função que representa o termo geral de uma progressão geométrica, com $a_{n}>0$.

Figura 28 - Gráficos da função que representa o termo geral de uma PG.
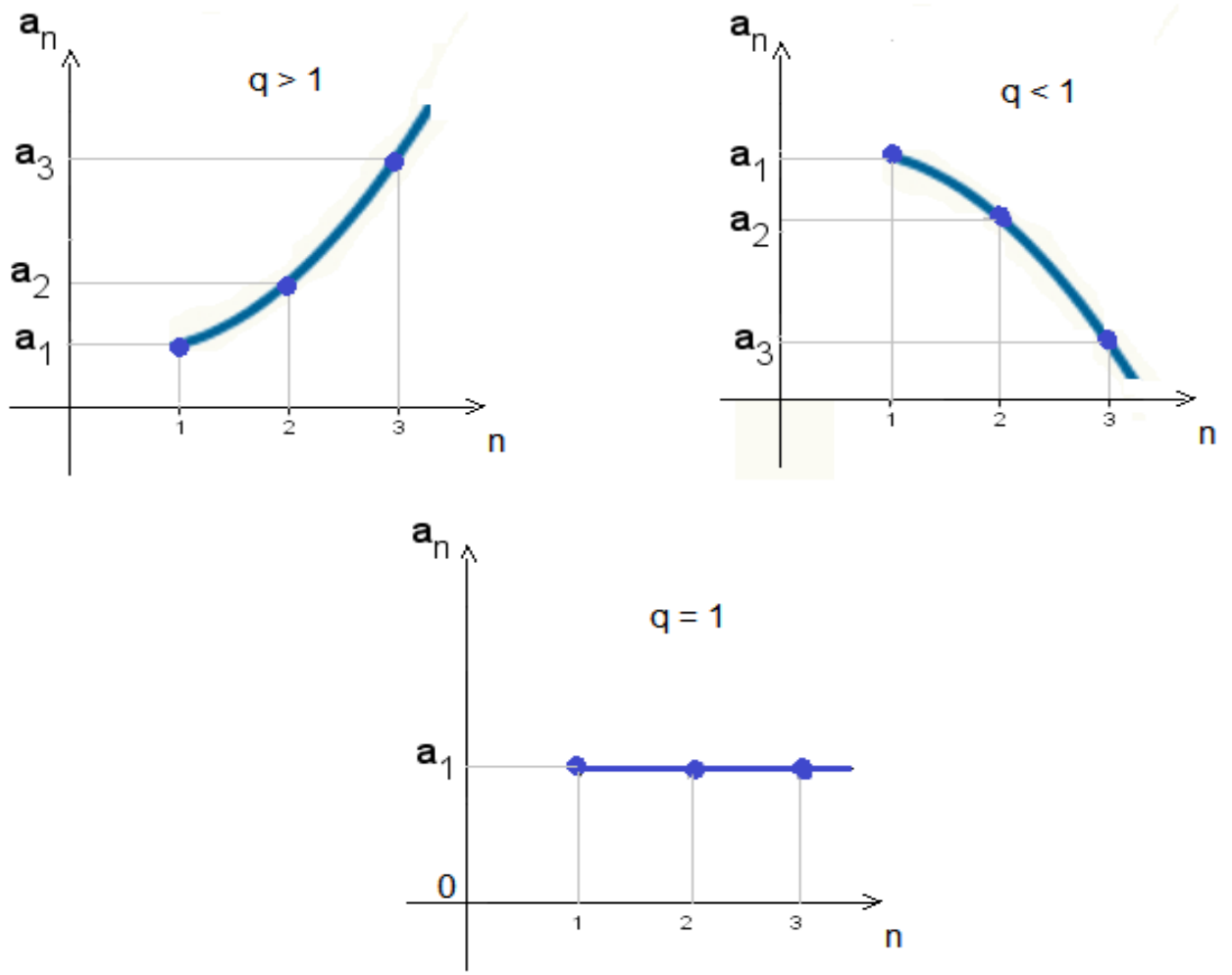

Fonte: Elaboração própria 


\section{4. Recorrências}

Geralmente, o estudo sobre sequências, no ensino médio, trata apenas de uma introdução ao estudo das progressões, com alguns exemplos e dedução das regras que as definem. Exibir a definição de recorrência para os alunos e resolver alguns problemas que desenvolvam o raciocínio recursivo pode tornar essa introdução mais interessante.

Uma sequência definida por recorrência é aquela por meio da qual, a partir de uma regra, calculamos um termo em função do anterior ou dos anteriores. (MORGADO; CARVALHO, 2013). Veja os exemplos a seguir:

$$
\begin{aligned}
& \text { (i) } \quad x_{n+1}=x_{n}+1 \text { sendo } x_{1}=1 \rightarrow(1,2,3,4, \ldots) \\
& \text { (ii) } x_{n+1}=3 . x_{n} \text { sendo } x_{1}=1 \rightarrow(1,3,9,27, \ldots) \\
& \text { (iii) } x_{n+1}=(n+1) x_{n}+n \text {, sendo } x_{1}=1 \rightarrow(1,3,11,47, \ldots) \\
& \text { (iv) } x_{n+2}=x_{n+1}+x_{n} \text {, sendo } x_{1}=1 \text { e } x_{2}=2 \rightarrow(1,2,3,5,8, \ldots)
\end{aligned}
$$

Nos itens (i), (ii) e (iii), temos exemplos de recorrências de primeira ordem, pois $x_{n+1}$ é expresso em função de $x_{n}$. Mais especificamente, os exemplos (i) e (ii) representam progressões - aritmética e geométrica, respectivamente. Já o item (iv) é uma recorrência de segunda ordem, pois $x_{n+2}$ é expresso em função de $x_{n}$ e $x_{n+1}$.

Vamos resolver dois problemas clássicos de aplicação de recorrências que desenvolvem a visualização geométrica e o raciocínio. Os problemas foram adaptados do livro Matemática Discreta - Coleção PROFMAT, de Augusto César Morgado e Paulo Cezar Pinto Carvalho (2013):

PROBLEMA 1: Seja $x_{n}$ o número máximo de regiões em que $n$ retas podem dividir o plano. Caracterize $x_{n}$ recursivamente, encontre uma fórmula fechada e a demonstre.

\section{SOLUÇÃO:}

Para que o plano se divida no maior número possível de regiões, devemos traçar as retas de maneira que cortem todas as outras traçadas anteriormente, sem passar por nenhuma interseção. O esboço das primeiras possibilidades está exibido na figura 29. 
Figura 29 - Primeiras divisões do plano por retas.

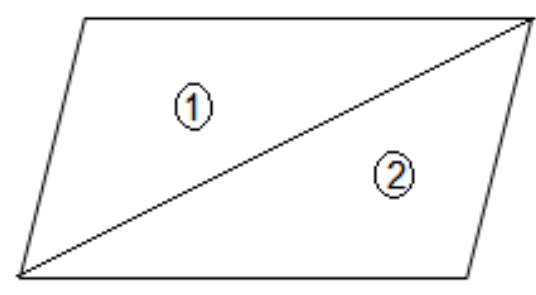

1 reta

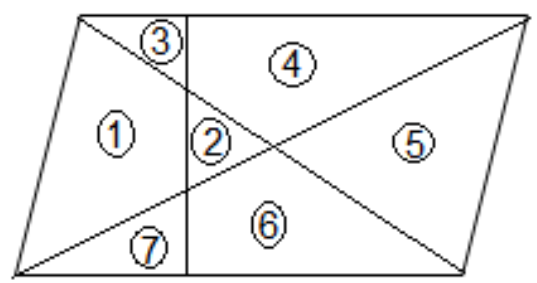

3 retas
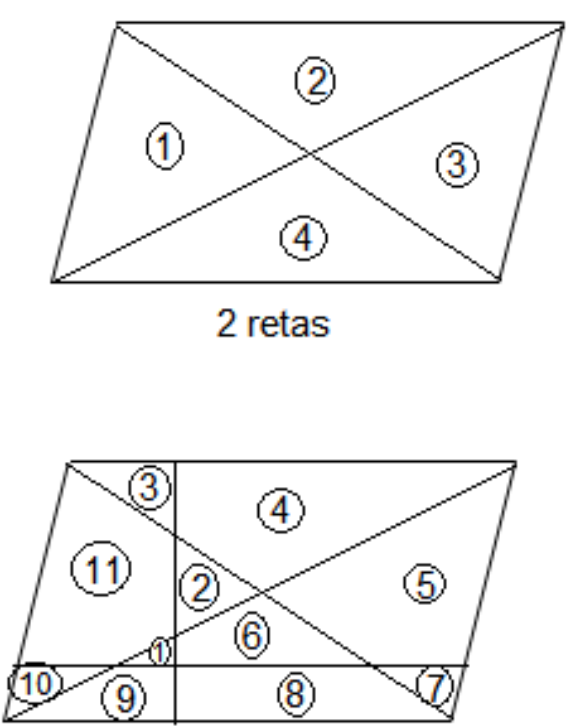

4 retas

Fonte: Elaboração própria

Daí, temos:

(a) Para uma reta temos: $n=1$ e $x_{1}=2$

(b) Para duas retas temos: $n=2$ e $x_{2}=4$

(c) Para três retas temos: $n=3$ e $x_{3}=7$

(d) Para quatro retas temos: $n=4$ e $x_{4}=11$

Como $\mathrm{n}$ pontos dividem uma reta em $n+1$ partes, um novo corte vai subdividir as $n+1$ regiões existentes. Criamos, assim, $n+1$ regiões a mais. $\mathrm{Ou}$ seja, teremos a seguinte definição recursiva:

$$
x_{n+1}=x_{n}+(n+1)
$$

Vamos agora encontrar uma fórmula fechada para essa recorrência, desenvolvendo os termos:

$$
\begin{gathered}
x_{1}=2 \\
x_{2}=x_{1}+2 \\
x_{3}=x_{2}+3 \\
\vdots \\
x_{n}=x_{n-1}+n
\end{gathered}
$$


Somando essas $n$ equações e aplicando a fórmula da soma dos termos de uma PA, temos:

$$
\begin{aligned}
& x_{n}=2+2+3+\cdots+n \\
& \therefore \quad x_{n}=1+(1+2+3+\cdots+n) \\
& \therefore \quad x_{n}=1+\frac{(1+n) \cdot n}{2} \\
& \therefore \quad x_{n}=\frac{n^{2}+n+2}{2}
\end{aligned}
$$

Vamos provar a fórmula por indução:

(i) Base da indução: $x_{1}=\frac{1^{2}+1+2}{2}=2$ OK

(ii) Hipótese da indução: suponha válido $x_{n}=\frac{n^{2}+n+2}{2}$

Pela definição recursiva, temos: $x_{n+1}=x_{n}+(n+1)$

Logo:

$$
\begin{gathered}
x_{n+1}=\frac{n^{2}+n+2}{2}+(n+1) \\
\therefore \quad x_{n+1}=\frac{n^{2}+n+2+2 n+2}{2} \\
\therefore \quad x_{n+1}=\frac{n^{2}+3 n+4}{2} \\
\therefore \quad x_{n+1}=\frac{(n+1)^{2}+(n+1)+2}{2}
\end{gathered}
$$

Logo $x_{n}=\frac{n^{2}+n+2}{2}$ é válido para todo $\mathrm{n}$ natural. 
PROBLEMA 2: Seja $x_{n}$ o número máximo de regiões em que $n$ círculos podem dividir o plano. Caracterize $x_{n}$ recursivamente, encontre uma fórmula fechada e a demonstre.

\section{SOLUÇÃO:}

Para que o plano se divida no maior número possível de regiões, devemos traçar os círculos de maneira que cortem todos os outros traçados anteriormente, sem passar por nenhum ponto de interseção. O esboço das primeiras possibilidades está exibido na figura 30.

Figura 30 - Primeiras divisões do plano por círculos.

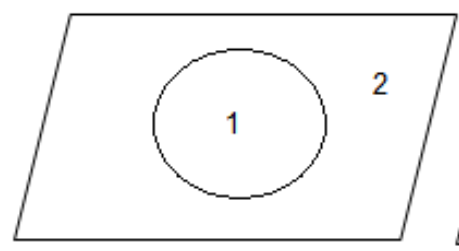

1 círculo

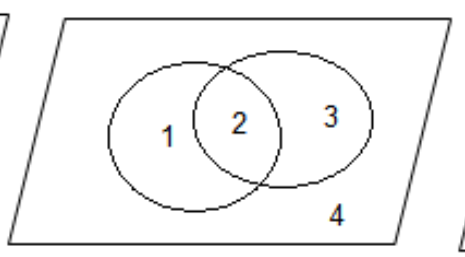

2 círculos

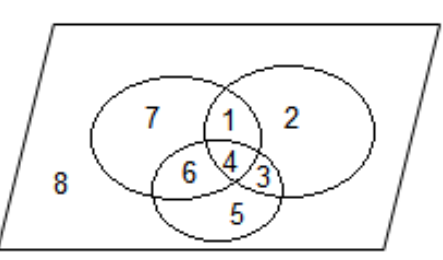

3 círculos

Fonte: Elaboração própria

Daí, temos:

(a) Para um círculo temos: $n=1$ e $x_{1}=2$

(b) Para dois círculos temos: $n=2$ e $x_{2}=4$

(c) Para três círculos temos: $n=3$ e $x_{3}=8$

A cada inclusão de círculo, temos a quantidade de regiões da etapa anterior, acrescida do dobro de círculos anteriormente existentes. Ou seja, teremos a seguinte definição recursiva:

$$
x_{n+1}=x_{n}+2 \cdot n
$$

Vamos agora encontrar uma fórmula fechada para essa recorrência, desenvolvendo os termos: 


$$
\begin{gathered}
x_{1}=2 \\
x_{2}=x_{1}+2 \\
x_{3}=x_{2}+4 \\
\vdots \\
x_{n}=x_{n-1}+2(n-1)
\end{gathered}
$$

Somando as equações, temos:

$$
\begin{gathered}
x_{n}=2+2+4+6+\cdots+2(n-1) \\
\therefore \quad x_{n}=2+(2+4+6+\cdots+2(n-1)) \\
\therefore \quad x_{n}=2+\frac{(2+2 n-2) \cdot(n-1)}{2} \\
\therefore \quad x_{n}=n^{2}-n+2
\end{gathered}
$$

Vamos provar a fórmula por indução:

(i) Base da indução: $x_{1}=1^{2}-1+2=2$ OK

(ii) Hipótese da indução: suponha válido $x_{n}=n^{2}-n+2$

Pela definição recursiva, temos: $x_{n+1}=x_{n}+2 n$

Logo:

$$
\begin{gathered}
x_{n+1}=n^{2}-n+2+2 n \\
\therefore \quad x_{n+1}=n^{2}+n+2 \\
\therefore \quad x_{n+1}=(n+1)^{2}-(n+1)+2
\end{gathered}
$$

Logo $x_{n}=n^{2}-n+2$ é válido para todo $\mathrm{n}$ natural. 


\section{4 \\ Coletânea de atividades para a educação básica com características fractais}

Neste capítulo apresentaremos sugestões de atividades que explorem variados conceitos matemáticos, destacando o processo de repetição existente nos fractais. Portanto, as imagens exibidas não constituem fractais propriamente ditos, por não possuírem a autossemelhança. Porém, como são aplicações para a educação básica, esperamos introduzir a característica da iteração, abrindo o caminho, para que no futuro, um trabalho mais formal possa ser feito com os alunos.

Uma proposta de solução para cada uma delas (exceto a atividade 1) encontra-se ao final do trabalho em apêndices. 
4.1.

Atividade 1: Conhecendo fractais

a) NÍVEL DE DIFICULDADE: básico.

b) ANO MÍNIMO DE ESCOLARIDADE: 6ํano do ensino fundamental.

c) OBJETIVO: apresentar o tema, destacando o processo de repetição de um fractal.

d) CONTEÚDOS MATEMÁTICOS ENVOLVIDOS:

$>$ Características de um fractal.

e) HABILIDADES QUE PODEM SER DESENVOLVIDAS:

> Fluência e participação em debates.

$>$ Interpretação de imagens.

$>$ Criatividade.

$>$ Raciocínio lógico.

f) SUGESTÕES AO PROFESSOR:

> Esta atividade é praticamente toda em forma de conversa, portanto, o que será apresentado a seguir é um roteiro do que pode ser conversado. O objetivo é fazer os alunos entrarem em contato pela primeira vez com os fractais e despertar sua curiosidade, mas o professor pode fazer as perguntas por escrito se assim julgar pertinente.

> A construção citada pode ser feita com qualquer material, assim como no computador ou simplesmente desenhado. 


\section{CONHECENDO FRACTAIS}

1) Exibir o vídeo do endereço https://globoplay.globo.com/v/4101257/, que apresenta a definição de fractal de maneira informal, com palavras fáceis. Mostra também a inspiração na natureza. O tema é apresentado até o tempo 04:15.

2) Iniciar a conversa perguntando aos alunos que tema foi apresentado no vídeo e o que cada um aprendeu.

3) Apresentar as imagens abaixo e perguntar aos alunos se elas podem ser consideradas exemplos de fractais.

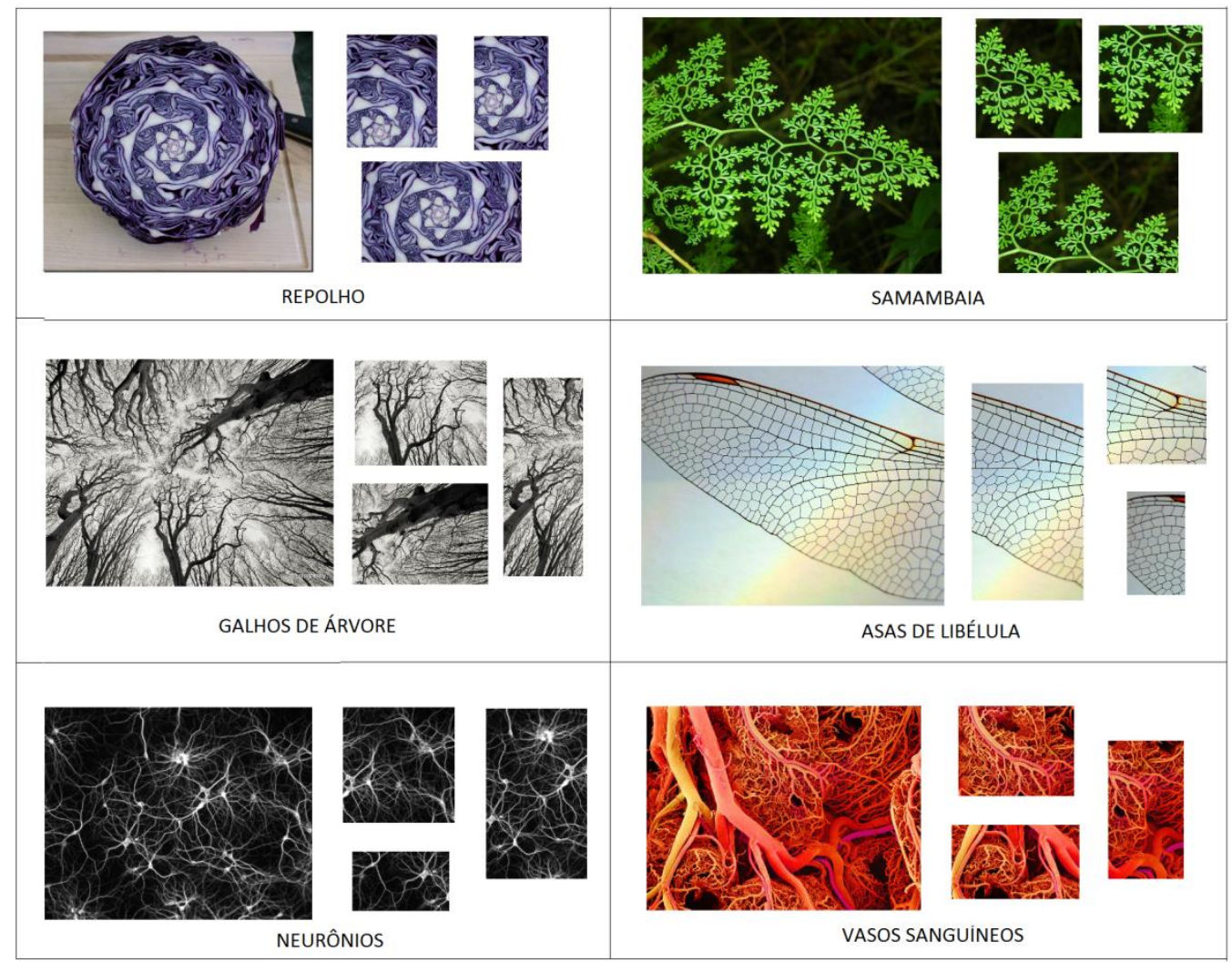

Fonte: adaptado de www.mdig.com.br, acesso em 5 de janeiro de 2017.

4) Continuar a conversa, perguntando o que os alunos já conheciam sobre essa geometria e se acham interessante estudá-la.

5) Exibir imagens dos fractais a seguir para que os alunos tenham mais referências para as próximas perguntas. 

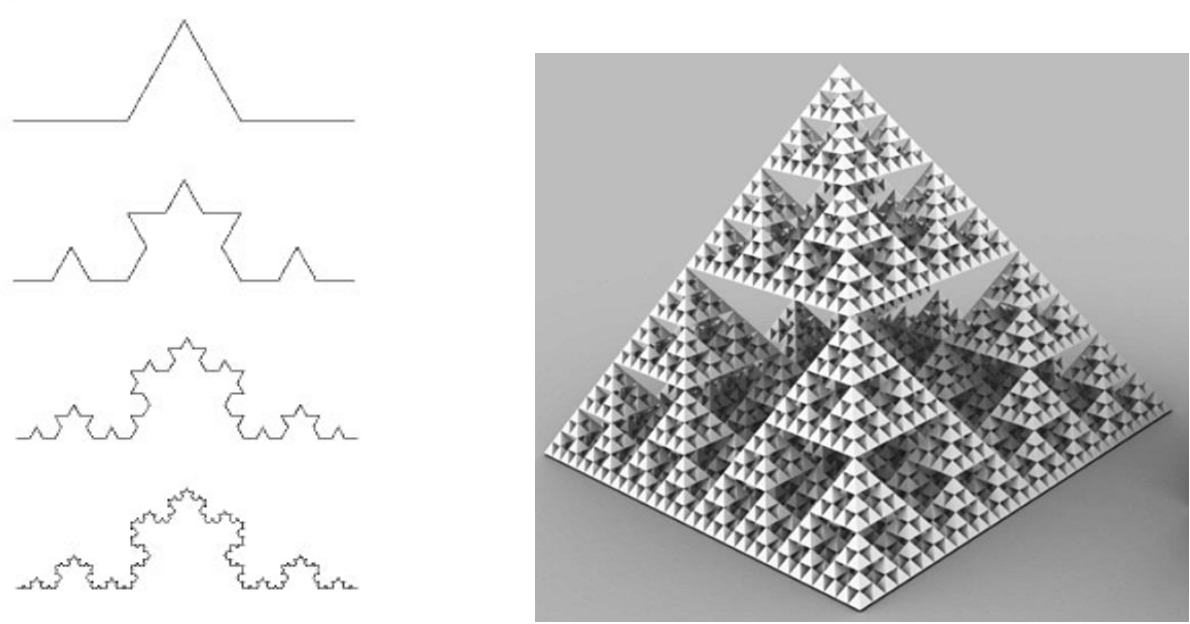

Fonte: www.hierophant.com.br, acesso em 03 de abril de 2017.

Fonte: www.comp.nus.edu.sg, acesso em 06 de abril de 2017.
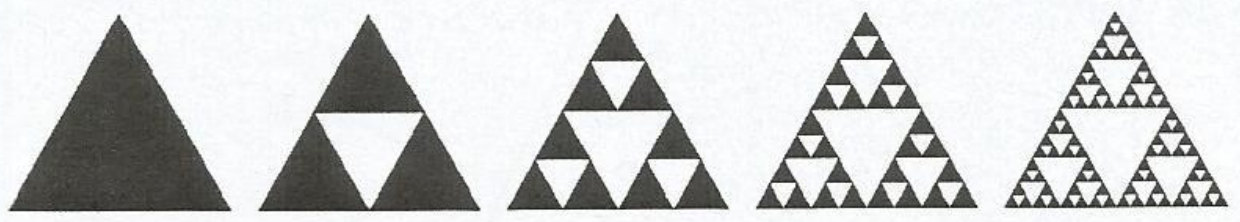

Fonte: JANOS, 2008.
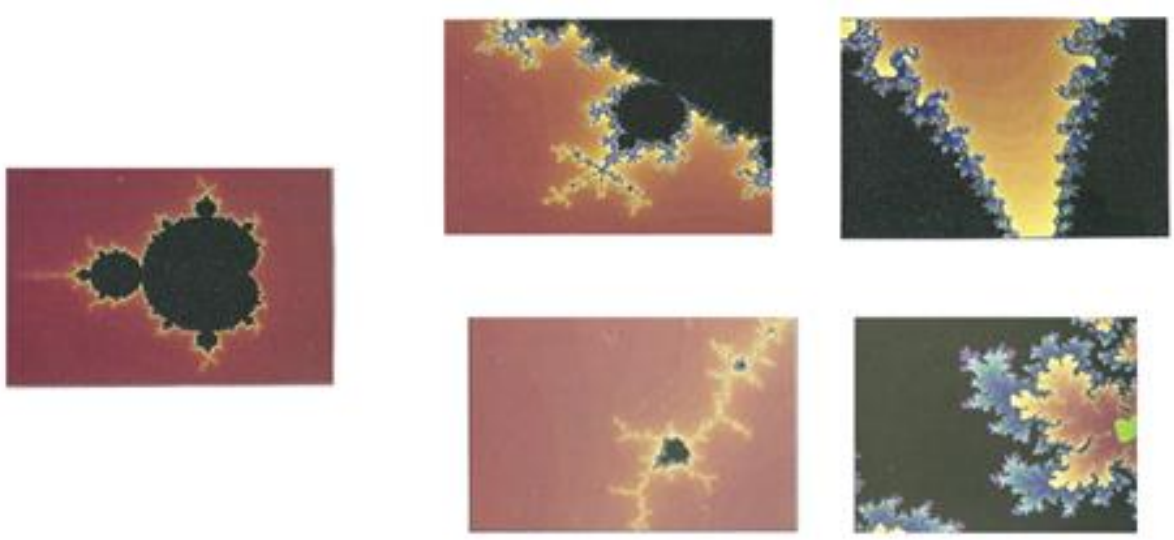

Fonte: JANOS, 2008.

6) Baseado no vídeo e em todas as imagens, peça aos alunos exemplos de conteúdos matemáticos que eles acham que podemos estudar através dos fractais. Pergunte, finalmente, como eles definiriam um fractal.

7) Levando em consideração a definição e tudo o que foi exibido, peça aos alunos que construam formas que possuam algumas das características de fractais. Utilize canudos plásticos e um papel cartão para fixá-los. 
4.2.

Atividade 2: Desenhando um fractal

a) NÍVEL DE DIFICULDADE: básico.

b) ANO MÍNIMO DE ESCOLARIDADE: 6ํano do ensino fundamental.

c) OBJETIVO: introduzir o tema, construindo um fractal com os passos dados e a partir disso, ser capaz de caracterizá-lo.

d) CONTEÚDOS MATEMÁTICOS ENVOLVIDOS:

Segmento de reta.

$>$ Divisão.

$>$ Processo iterativo.

$>$ Características de um fractal.

e) HABILIDADES QUE PODEM SER DESENVOLVIDAS:

$>$ Desenho.

$>$ Interpretação de texto.

$>$ Criatividade.

$>$ Raciocínio lógico.

f) SUGESTÕES AO PROFESSOR:

> A atividade pode ser aplicada nas séries iniciais do ensino fundamental com as devidas adaptações de linguagem.

$>$ Imagens de fractais podem ser exibidas durante a atividade. 


\section{DESENHANDO UM FRACTAL}

1) Desenhe um segmento de reta com $8 \mathrm{~cm}$ de comprimento.

2) No "topo" do segmento, desenhe outros dois outros segmentos, em forma de "V", com comprimento igual à metade do segmento anterior.

3) Com comprimento igual à metade dos últimos segmentos desenhados, faça outros dois, no "topo" de cada segmento do "V" construído.

4) Repita esse processo mais duas vezes. Você formará uma espécie de árvore e construirá um fractal.

5) Agora vamos analisar essa formação. Responda:

a) Se coubesse no papel, você poderia continuar seguindo o processo e desenhando? Quantas vezes?

b) A regra a que você teve que obedecer para desenhar foi sempre a mesma? Teve um padrão?

c) Com base na construção e nas perguntas anteriores, você é capaz de dizer o que é um fractal?

6) Vamos refletir sobre a variação que um fractal pode ter. Responda:

a) Podemos iniciar com o segmento em outra posição?

b) A divisão dos segmentos precisa ser ao meio?

c) Podemos usar outros elementos geométricos que não seja a reta? Quais, por exemplo?

7) Com a ajuda das perguntas anteriores, desenhe outro fractal inspirado no que já foi construído e procure explicar sua construção. 
4.3.

Atividade 3: Pentágonos e estrelas inspirados em fractais

a) NÍVEL DE DIFICULDADE: intermediário para o $7^{\circ}$ ano, pois exige dedução e generalização de cálculos, algo abstrato para uma turma que está iniciando o estudo da álgebra. A partir do $8^{\circ}$ ano, a atividade pode ser considerada de nível básico, pois os alunos já estão acostumados com as variáveis algébricas.

b) ANO MÍNIMO DE ESCOLARIDADE: $7^{\circ}$ ano do ensino fundamental.

c) OBJETIVO: aplicar e reforçar os conteúdos envolvidos.

d) CONTEÚDOS MATEMÁTICOS ENVOLVIDOS:

Polígono e seus elementos.

$>$ Contagem.

$>$ Escrita de expressões algébricas que generalizam um problema.

> Valor numérico de expressões algébricas.

$>$ Preenchimento e interpretação de tabelas.

$>$ Processo iterativo.

e) HABILIDADES QUE PODEM SER DESENVOLVIDAS:

$>$ Visualização geométrica.

$>$ Raciocínio lógico.

f) SUGESTÕES AO PROFESSOR:

> Os alunos podem continuar os desenhos para mais algumas etapas, inclusive iniciando com outro polígono. 
$\mathrm{Na}$ figura abaixo, temos três etapas de uma construção repetitiva iniciada por um pentágono.

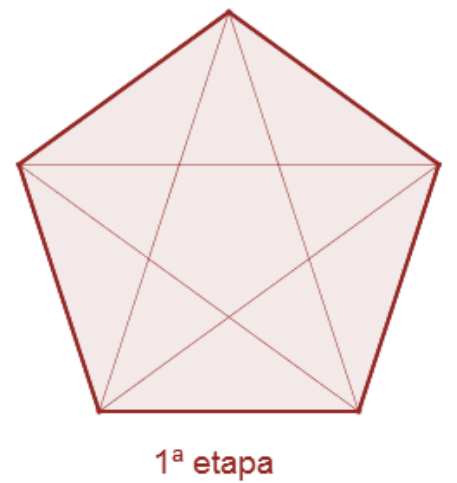

$1^{\mathrm{a}}$ etapa

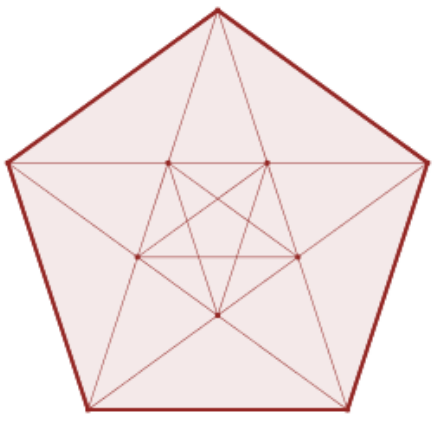

$2^{a}$ etapa

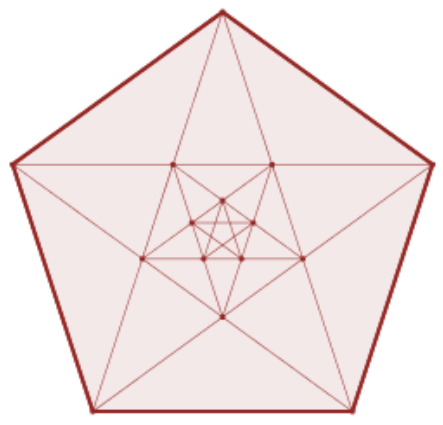

$3^{\text {a }}$ etapa

Fonte: Elaboração própria

1) A estrela desenhada no interior do pentágono é formada por segmentos de reta que representam um elemento de polígono. Que elemento é esse?

2) Através da imagem, você é capaz de deduzir a regra de construção dessa repetição?

3) Vamos contar alguns elementos:

a) Quantos pentágonos regulares temos na $1^{\text {a }}$ etapa?

b) Quantas estrelas temos na 1a etapa?

c) Quantos triângulos foram formados no interior da figura da $1^{\text {a }}$ etapa? Não considere aqueles formados pela união de triângulos menores, ou que tenham segmentos de reta em seu interior. Dica: conte os triângulos pequenos em volta do pentágono central da estrela.

d) Quantos pentágonos regulares temos na $2^{\underline{a}}$ etapa?

e) Quantas estrelas temos na $2^{\underline{a}}$ etapa?

f) Quantos triângulos foram formados no interior da figura da $2^{\underline{a}}$ etapa? Não considere aqueles formados pela união de triângulos menores, ou que tenham segmentos de reta em seu interior. Dica: conte os triângulos pequenos em volta do pentágono central de cada estrela.

g) Quantos pentágonos regulares temos na 3a etapa?

h) Quantas estrelas temos na 3를 
i) Quantos triângulos foram formados no interior da figura da $3^{\text {a }}$ etapa? Não considere aqueles formados pela união de triângulos menores, ou que tenham segmentos de reta em seu interior. Dica: conte os triângulos pequenos em volta do pentágono central de cada estrela.

4) Preencha a tabela abaixo com os valores respondidos anteriormente:

\begin{tabular}{|c|l|l|l|}
\hline ETAPA & PENTÁGONOS & ESTRELAS & TRIÂNGULOS \\
\hline 1 & & & \\
\hline 2 & & & \\
\hline 3 & & & \\
\hline
\end{tabular}

5) Com base na tabela, complete as sentenças:

a) A quantidade de pentágonos em uma etapa é igual ao número da etapa mais Portanto, se chamarmos a etapa desejada de $n$, teremos pentágonos.

b) A quantidade de estrelas em uma etapa é igual ao número de cada . Portanto, se chamarmos a etapa desejada de $n$, teremos estrelas.

c) A quantidade de triângulos em uma etapa é igual a vezes 0 número da etapa. Portanto, se chamarmos a etapa desejada de $\mathrm{n}$, teremos triângulos.

6) Baseado nas generalizações anteriores, preencha a tabela a seguir com as quantidades das etapas solicitadas:

\begin{tabular}{|c|l|l|l|}
\hline ETAPA & PENTÁGONOS & ESTRELAS & TRIÂNGULOS \\
\hline 5 & & & \\
\hline 20 & & & \\
\hline 431 & & & \\
\hline 6.798 & & & \\
\hline
\end{tabular}


4.4.

Atividade 4: Quadrados inspirados em fractais

a) NÍVEL DE DIFICULDADE: intermediário.

b) ANO MÍNIMO DE ESCOLARIDADE: 9ํano do ensino fundamental.

c) OBJETIVO: aplicar e reforçar os conteúdos envolvidos.

d) CONTEÚDOS MATEMÁTICOS ENVOLVIDOS:

$>$ Ponto médio.

$>$ Teorema de Pitágoras.

$>$ Perímetro de polígono.

$>$ Área de polígono.

$>$ Razão.

$>$ Cálculos com raiz irracional.

$>$ Preenchimento e interpretação de tabelas

$>$ Processo iterativo.

e) HABILIDADES QUE PODEM SER DESENVOLVIDAS:

> Visualização geométrica.

f) SUGESTÕES AO PROFESSOR:

$>$ Essa construção é fácil de ser feita com material concreto, canudos por exemplo. O professor pode substituir a imagem pela construção real. 


\section{QUADRADOS INSPIRADOS EM FRACTAIS}

A imagem a seguir foi iniciada com o quadrado $A B C D$ de $8 \mathrm{~cm}$ de lado e, a partir do ponto médio de cada lado, construímos um novo quadrado, interno ao anterior. Esse processo foi repetido até que se formassem cinco quadrados no total.

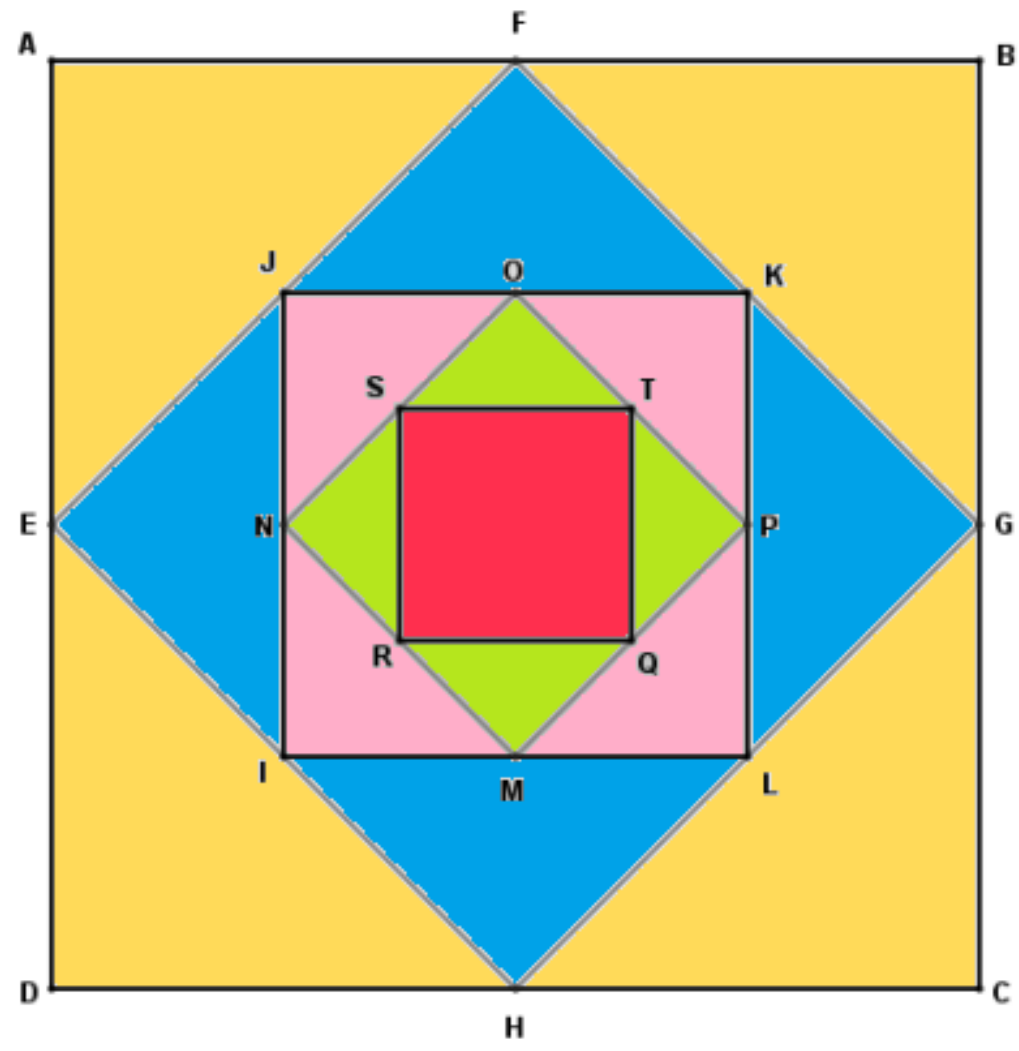

Fonte: Elaboração própria

1) Baseado na imagem, e sem utilizar qualquer material como régua ou calculadora, responda as questões:

a) Qual a medida do segmento AF?

b) Que outros segmentos possuem a mesma medida?

c) Como você pode calcular a medida do lado do quadrado EFGH? Calcule.

d) Qual a medida do segmento EJ?

e) Que outros segmentos possuem a mesma medida?

f) Utilizando o mesmo conceito do item (c), qual a medida do lado do quadrado IJKL?

g) Qual a medida do segmento IN?

h) Que outros segmentos possuem a mesma medida? 
i) Utilizando o mesmo conceito do item (c), qual a medida do lado do quadrado MNOP?

j) Qual a medida do segmento MR?

k) Que outros segmentos possuem a mesma medida?

I) Utilizando o mesmo conceito do item (c), qual a medida do lado do quadrado QRST?

2) Preencha a tabela a seguir, calculando o perímetro e a área de cada um dos cinco quadrados do fractal:

\begin{tabular}{|c|c|c|c|}
\hline QUADRADO & $\begin{array}{c}\text { LADO DO } \\
\text { QUADRADO }\end{array}$ & $\begin{array}{c}\text { PERÍMETRO DO } \\
\text { QUADRADO }\end{array}$ & $\begin{array}{c}\text { ÁREA DO } \\
\text { QUADRADO }\end{array}$ \\
\hline $1(\mathrm{ABCD})$ & $8 \mathrm{~cm}$ & & \\
\hline $2(\mathrm{EFGH})$ & & & \\
\hline $3(\mathrm{IJKL})$ & & & \\
\hline $4(\mathrm{MNOP})$ & & & \\
\hline $5(\mathrm{QRST})$ & & & \\
\hline
\end{tabular}

3) Com base na tabela anterior, responda:

a) Qual a razão entre o lado de um quadrado e do anterior?

b) Qual a razão entre o perímetro de um quadrado e do anterior?

c) Qual a razão entre a área de um quadrado e do anterior?

d) Que relação existe entre a razão dos lados e do perímetro?

e) Que relação existe entre a razão dos lados e da área? 
4) Baseado nas razões anteriores, repita os dados preenchidos do último quadrado e complete com as três etapas seguintes:

\begin{tabular}{|c|c|c|c|}
\hline QUADRADO & $\begin{array}{c}\text { LADO DO } \\
\text { QUADRADO }\end{array}$ & $\begin{array}{c}\text { PERÍMETRO DO } \\
\text { QUADRADO }\end{array}$ & $\begin{array}{c}\text { ÁREA DO } \\
\text { QUADRADO }\end{array}$ \\
\hline 5 (QRST) & & & \\
\hline 6 & & & \\
\hline 7 & & & \\
\hline 8 & & & \\
\hline
\end{tabular}


4.5 .

Atividade 5: Circunferências inspiradas em fractais

a) NÍVEL DE DIFICULDADE: avançado.

b) ANO MÍNIMO DE ESCOLARIDADE: $1^{\circ}$ ano do ensino médio.

c) OBJETIVO: aplicar e reforçar os conteúdos envolvidos.

d) CONTEÚDOS MATEMÁTICOS ENVOLVIDOS:

Circunferência e seus elementos.

$>$ Divisão de um segmento em partes iguais.

$>$ Progressão geométrica.

$>$ Processo iterativo.

e) HABILIDADES QUE PODEM SER DESENVOLVIDAS:

$>$ Visualização geométrica.

$>$ Raciocínio lógico.

f) SUGESTÕES AO PROFESSOR:

$>$ Os alunos podem continuar os desenhos para mais algumas etapas. 
Observe as iterações abaixo, formadas por circunferências. Seja A o centro da primeira circunferência.
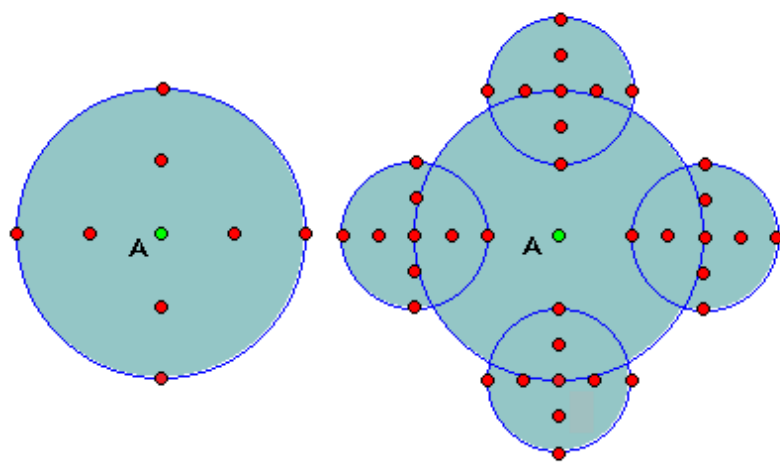

$1^{\mathrm{a}}$ iteração

$$
2^{\mathrm{a}} \text { iteração }
$$

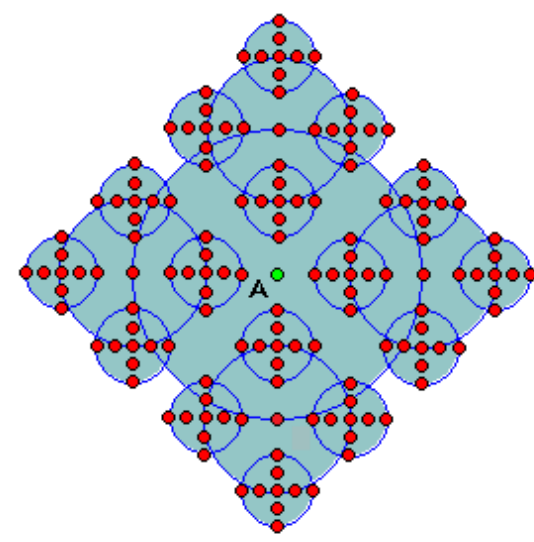

$3^{\mathrm{a}}$ iteração

Fonte: Adaptada de www.matematica.br/igeom, acesso em 17 de junho de 2017.

1) Na circunferência da primeira iteração, temos alguns pontos marcados. Eles estão sobre um elemento da circunferência que aparece duas vezes, formando uma espécie de cruz. Com base nessa informação, responda:

a) Que elemento é esse?

b) Quantos pontos aparecem sobre um deles?

c) Em quantas partes o elemento ficou dividido?

2) A partir da segunda iteração, novas circunferências foram construídas. Que ponto foi considerado o centro de cada uma delas e qual a medida do raio?

3) Baseado nas perguntas anteriores, você é capaz de dizer qual a regra de construção da repetição apresentada?

4) Escreva a sequência da quantidade de novas circunferências que foram construídas em cada iteração e responda:

a) Essa sequência é uma progressão aritmética ou geométrica?

b) Qual a razão dessa progressão?

c) Qual a fórmula geral dessa progressão? 
d) A fórmula geral encontrada anteriormente representa que tipo de função?

e) Qual a fórmula geral do total de circunferências em cada iteração?

5) Baseado nas fórmulas que você escreveu anteriormente, calcule:

a) A quantidade de novas circunferências que serão construídas na quarta iteração.

b) A quantidade de novas circunferências que serão construídas na sétima iteração.

c) O total de circunferências na terceira iteração.

d) O total de circunferências na sexta iteração.

6) Qual dos gráficos abaixo representa a função estabelecida pela fórmula do termo geral?

a)

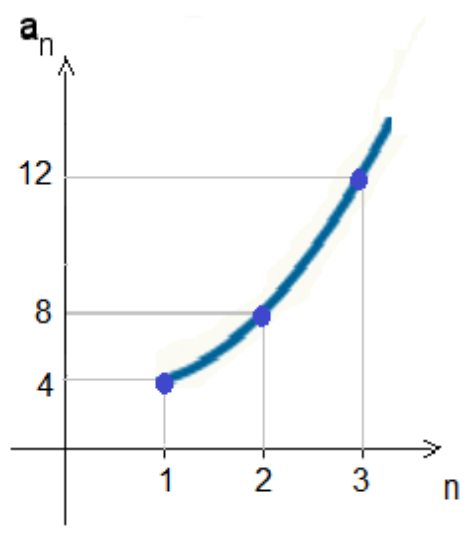

c)

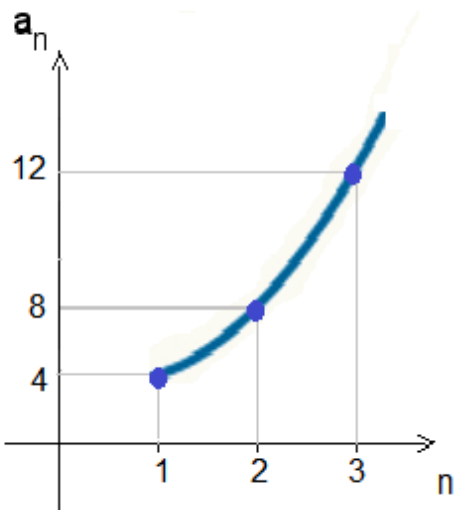

b)

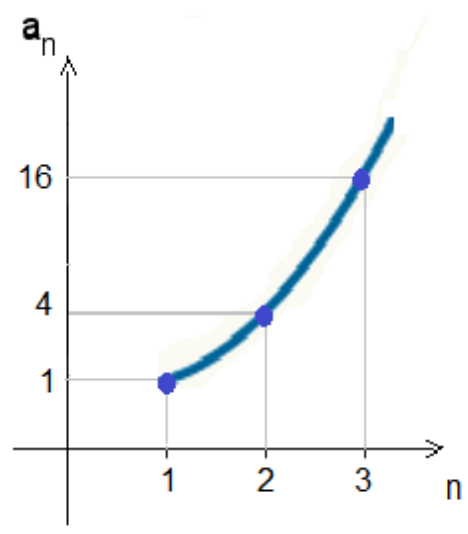

d)

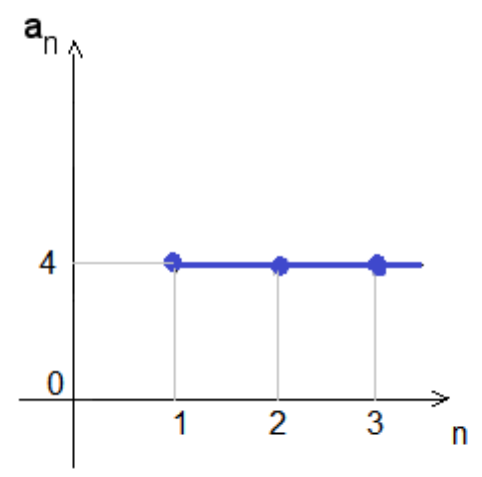


4.6.

Atividade 6: Paralelepípedos inspirados em fractais

a) NÍVEL DE DIFICULDADE: avançado.

b) ANO MÍNIMO DE ESCOLARIDADE: $1^{\circ}$ ano do ensino médio.

c) OBJETIVO: aplicar e reforçar os conteúdos envolvidos.

d) CONTEÚDOS MATEMÁTICOS ENVOLVIDOS:

> Paralelepípedo e seus elementos.

> Área e volume de paralelepípedo.

$>$ Progressão aritmética.

$>$ Processo iterativo.

e) HABILIDADES QUE PODEM SER DESENVOLVIDAS:

> Visualização geométrica.

f) SUGESTÕES AO PROFESSOR:

$>$ O professor pode levar paralelepípedos montados com as medidas propostas ou construir com os alunos. 
Observe a imagem abaixo, formada por três paralelepípedos. O paralelepípedo 1 possui $1 \mathrm{~cm}$ de altura, $3 \mathrm{~cm}$ de comprimento e $2 \mathrm{~cm}$ de largura. O paralelepípedo 2 tem $2 \mathrm{~cm}$ de altura, $6 \mathrm{~cm}$ de comprimento e $4 \mathrm{~cm}$ de largura. Já as dimensões do paralelepípedo 3 são: $3 \times 9 \times 6$, nessa mesma ordem.

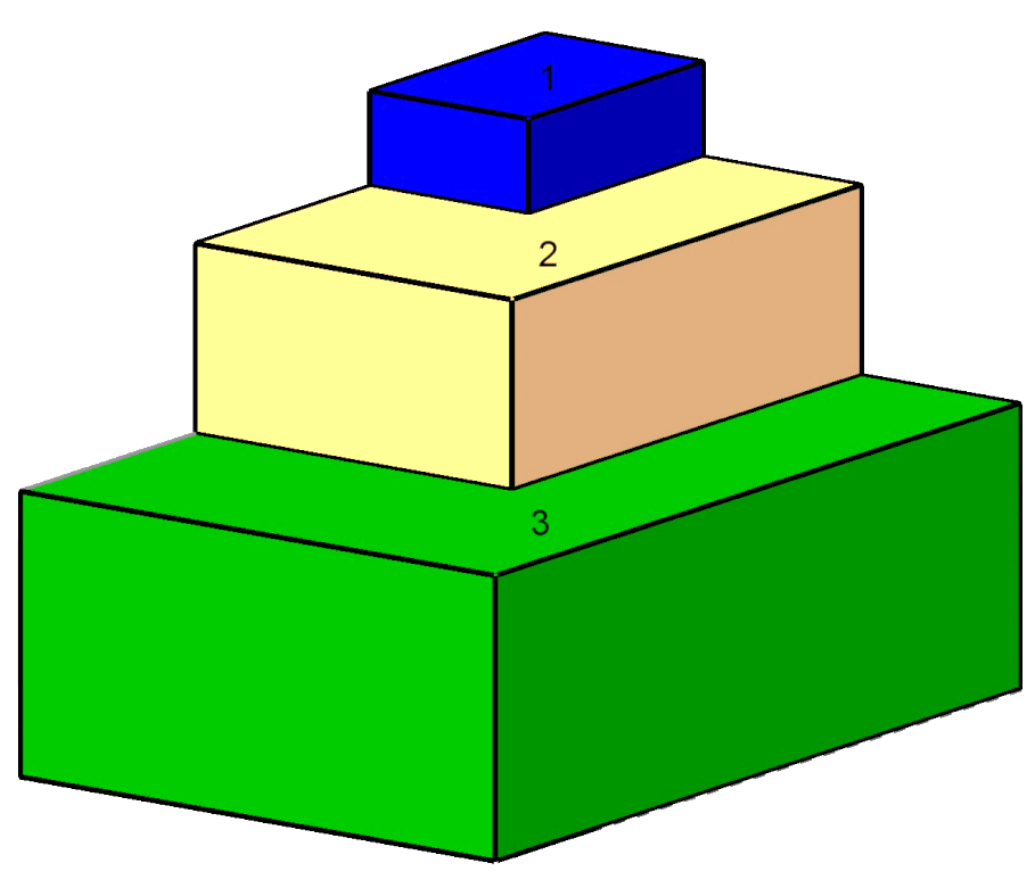

Fonte: Elaboração própria.

1) Calcule a área total das faces de cada paralelepípedo.

2) Calcule o volume de cada paralelepípedo.

3) Escreva a sequência formada pelas alturas dos paralelepípedos 1, 2, 3, respectivamente, e responda:

a) Essa sequência é uma progressão aritmética ou geométrica?

b) Qual a razão dessa progressão?

c) Qual a fórmula geral dessa progressão?

d) Qual será a altura do 15ํㅜ paralelepípedo? 
4) Escreva a sequência formada pelos comprimentos dos paralelepípedos $1,2,3$, respectivamente, e responda:

a) Essa sequência é uma progressão aritmética ou geométrica?

b) Qual a razão dessa progressão?

c) Qual a fórmula geral dessa progressão?

d) Qual será o comprimento do 10² paralelepípedo?

5) Escreva a sequência formada pelas larguras dos paralelepípedos 1, 2, 3 , respectivamente, e responda:

a) Essa sequência é uma progressão aritmética ou geométrica?

b) Qual a razão dessa progressão?

c) Qual a fórmula geral dessa progressão?

d) Qual será a largura do $12^{\circ}$ paralelepípedo?

6) Quais serão as dimensões do 9ำ paralelepípedo? E do 20?

7) Que tipo de função as fórmulas gerais encontradas no item (c) das questões (3), (4) e (5) representam? Elas são crescentes ou decrescentes?

8) Preencha a tabela a seguir, considerando a função que representa a fórmula geral de cada dimensão dos paralelepípedos:

\begin{tabular}{|c|c|c|c|}
\hline DIMENSÃO & FUNÇÃO & $\begin{array}{c}\text { COEFICIENTE } \\
\text { ANGULAR }\end{array}$ & $\begin{array}{c}\text { TERMO } \\
\text { INDEPENDENTE }\end{array}$ \\
\hline Altura & & & \\
\hline Comprimento & & & \\
\hline Largura & & & \\
\hline
\end{tabular}




\section{5 Aplicação no ensino e resultados}

Em novembro de 2016, a atividade 1, "conhecendo fractais" foi aplicada em uma escola da rede municipal do Rio de Janeiro, localizada no bairro de Honório Gurgel, zona norte da cidade. O local é bem estruturado fisicamente e possui muitos materiais pedagógicos e eletrônicos. A manutenção de equipamentos ou recursos como TV, internet, computadores e condicionadores de ar não é feita constantemente, principalmente por falta de verba. Assim, mesmo existindo todos esses aparatos, nem sempre estão disponíveis para uso. $\mathrm{Na}$ ocasião da aplicação da atividade, a escola funcionava em dois turnos, com aproximadamente 350 alunos no total, divididos em 10 turmas regulares e 2 turmas de projeto de aceleração dos estudos. Os estudantes, em geral, são de classe baixa, moradores das comunidades do entorno e com pouco acesso a variadas opções culturais. A turma na qual a atividade foi realizada era de $9^{\circ}$ ano do ensino fundamental, com 24 alunos presentes, entre 13 e 15 anos de idade, com disciplina regular.

A atividade foi escolhida, porque nenhum dos alunos presentes conhecia a geometria fractal ou tinha ouvido algo sobre o assunto. Portanto, uma introdução ao tema era necessária. Além disso, a atividade possui uma característica mais simples e descontraída, com conversa, atividade manual e conceitos matemáticos fáceis, o que atraiu mais os jovens necessitados de estímulo e incentivo aos estudos.

Ao iniciar a apresentação do vídeo, os alunos mostraram interesse e mantiveram a atenção. A metade final do conteúdo não discorre sobre fractais e sim sobre a geometria dos favos de mel e a sequência de Fibonacci - por essa razão o vídeo foi pausado. Porém, como se tratava de uma introdução e os estudantes ainda não sabiam exatamente sobre o que seria a atividade, pediram para assistir até o fim, mostrando que algo além dos fractais também despertou a atenção deles. Foi permitido que assistissem, pois todos os temas tinham a relação com a natureza em comum. Além disso, como a vontade de saber mais partiu dos próprios alunos, não seria agradável se isso fosse tirado deles. Foi um momento propício para o incentivo ao estudo da matemática. 
Após a exibição, as cadeiras foram organizadas em roda para criar um ambiente diferenciado para o início da conversa. Finalmente foi deixado explícito que o debate seria sobre os fractais, o que são e o que podemos estudar através deles. Os discentes puderam expor o que entenderam inicialmente sobre o tema. Todas as respostas foram básicas, algo como: "os fractais são coisas que vão se repetindo em qualquer tamanho", mas, ainda que de maneira rústica, tais respostas mostraram a compreensão por parte dos alunos. No desenrolar da conversa, participaram de maneira satisfatória, pareceram gostar do assunto e acharam interessante estudar mais sobre ele, já que todos disseram não conhecer nada anteriormente. Como o vídeo deu exemplos somente de fractais da natureza, se surpreenderam ao ver as imagens de diversos fractais e saber que outras construções eram possíveis. Foi uma ampliação bastante positiva do conhecimento.

O momento desfavorável da atividade foi quando os alunos tiveram que exemplificar conteúdos matemáticos que podem ser estudados através dos fractais. Nada além de "figuras" e "formas" foi dito. Eles viram imagens de fractais formados por segmentos de retas, triângulos, pirâmides e curvas e sequer citaram essas palavras ou algo relacionado. Apesar de compreenderem o processo de repetição infinita e a semelhança da geometria fractal, não conseguiram classificar esses itens como algo matemático. Foi necessária a intervenção direta da professora - citando esses e muitos outros exemplos.

O ponto alto da atividade foi, sem dúvida, a confecção dos fractais com a utilização de canudos plásticos. A ideia inicial da professora era que todos montassem o quadrado da atividade 4, proposta no capítulo anterior, ou seja, todos teriam a mesma construção. Com ela seria possível mostrar alguns conceitos básicos como quadrilátero, ponto médio e Teorema de Pitágoras, já que tiveram dificuldades em fazer associações matemáticas. Porém, os jovens demonstraram o desejo de construir imagens diferentes, pois já sabiam o que era um fractal e "era só repetir" (palavras deles). Isso serviu como avaliação da atividade. $O$ resultado foram construções criativas, que respeitavam o processo iterativo, mostrando que realmente tinham aprendido o conceito e atingido o objetivo proposto para a atividade. Para a confecção, os alunos se dividiram em 5 grupos. Exibiremos a seguir, fotos que apresentam o processo de construção e os produtos finais elaborados pelos estudantes. 
Figura 31 - Processo de construção do grupo 1.

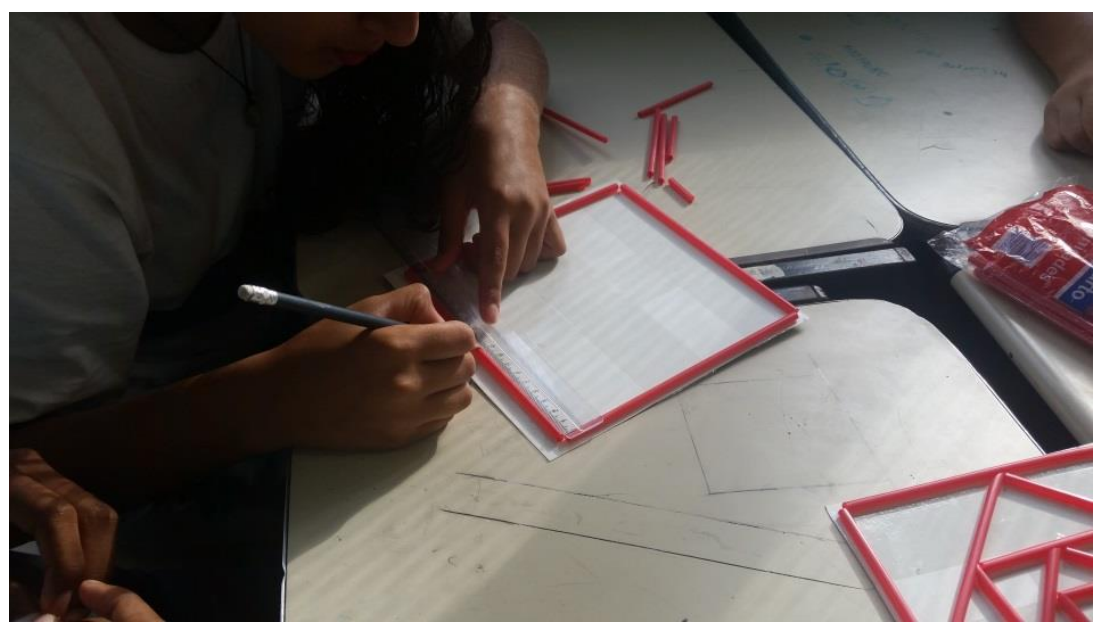

Figura 32 - Processo de construção do grupo 2.

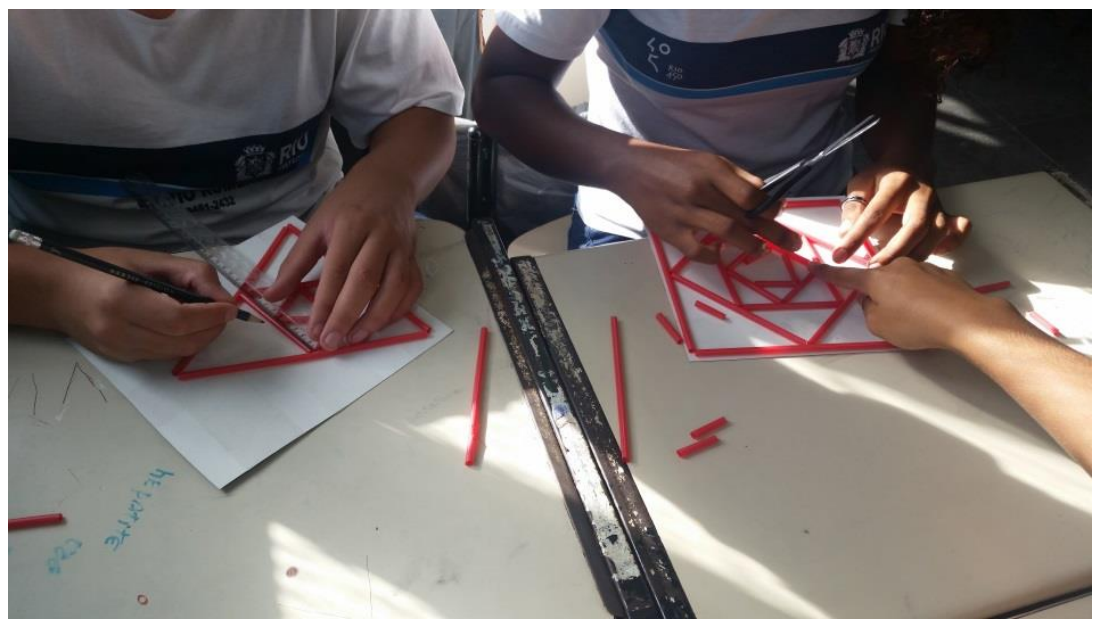

Figura 33 - Produtos finais dos grupos 1 e 2.

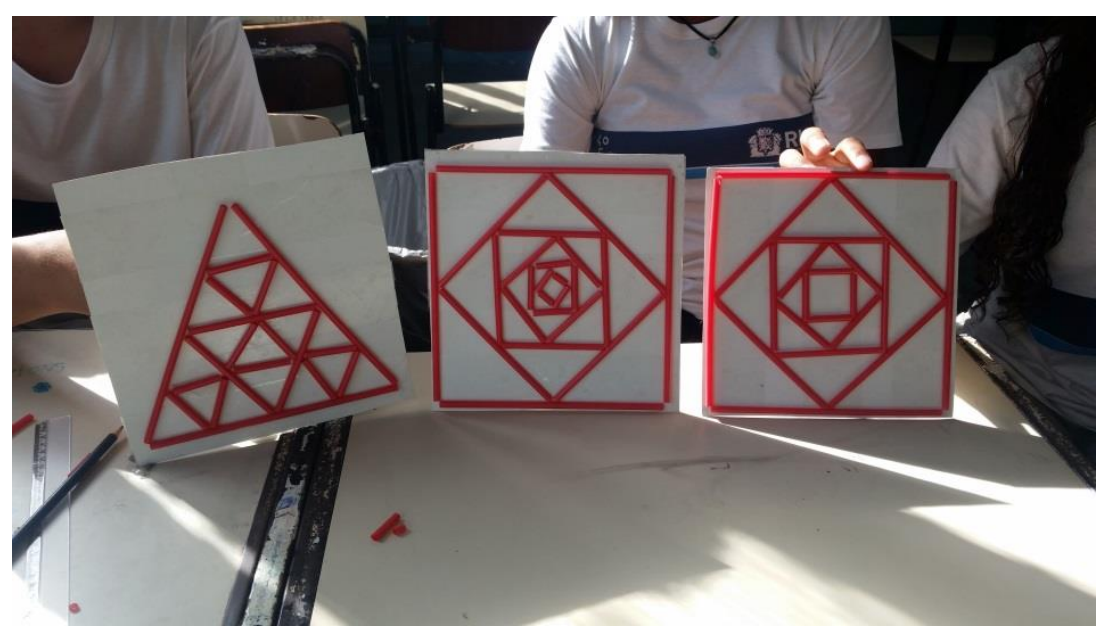


Figura 34 - Processo de construção do grupo 3.

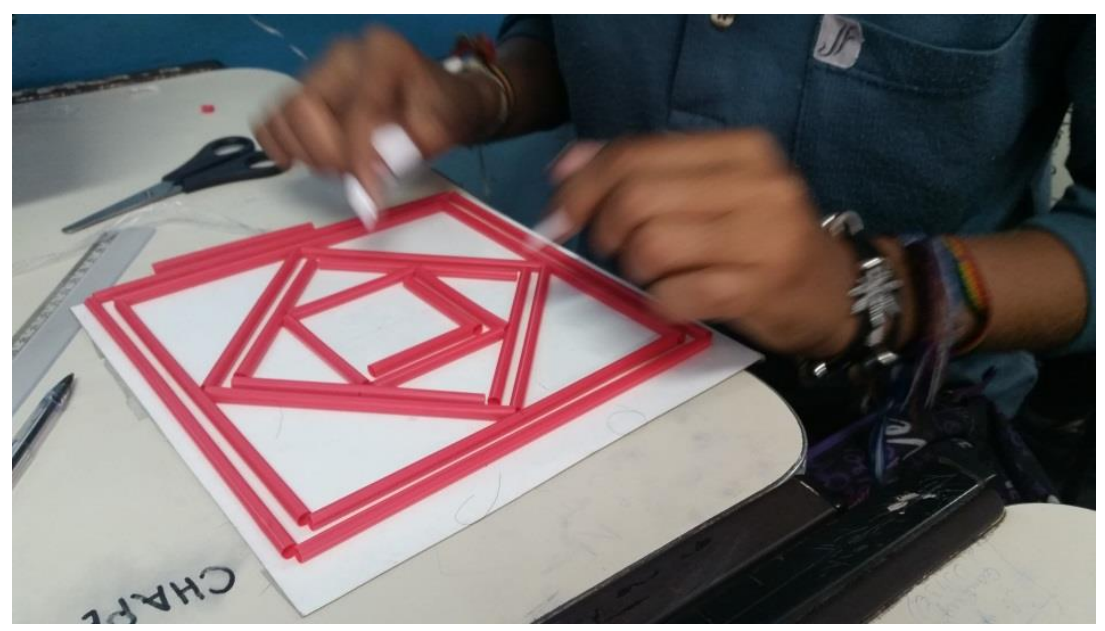

Figura 35 - Produto final do grupo 3.

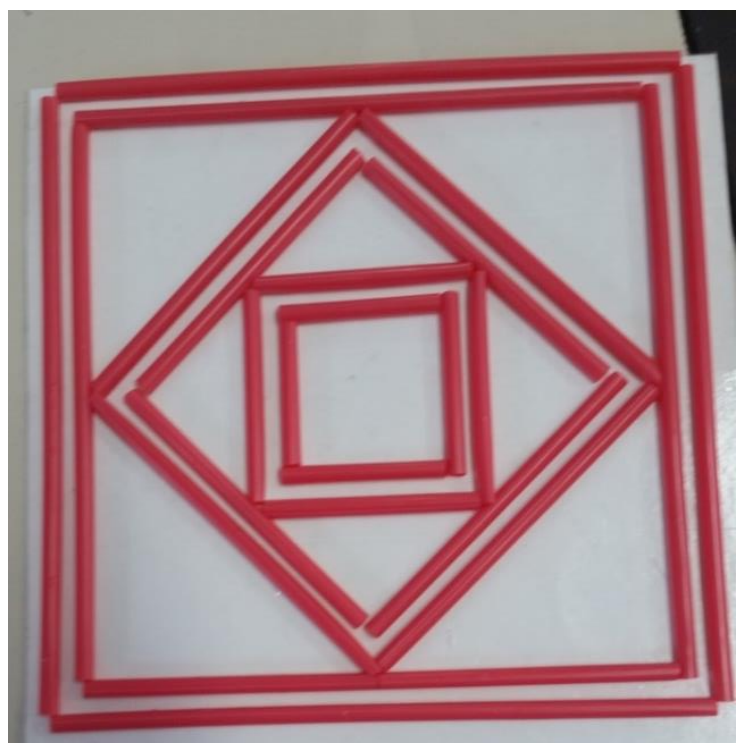

Figura 36 - Processo de construção do grupo 4.

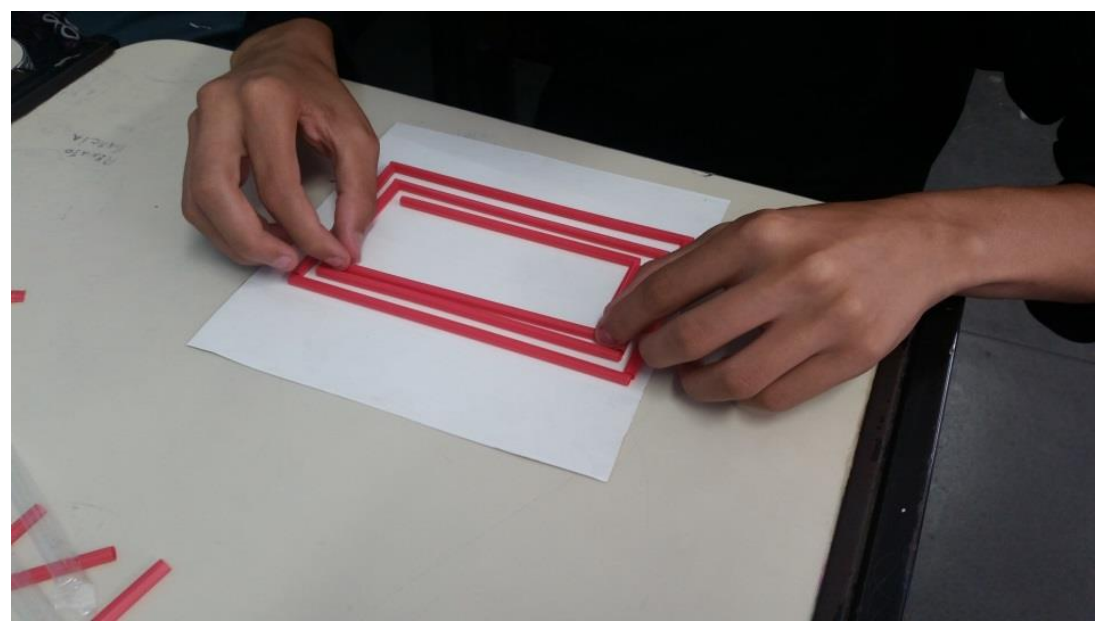


Figura 37 - Produto final do grupo 4.

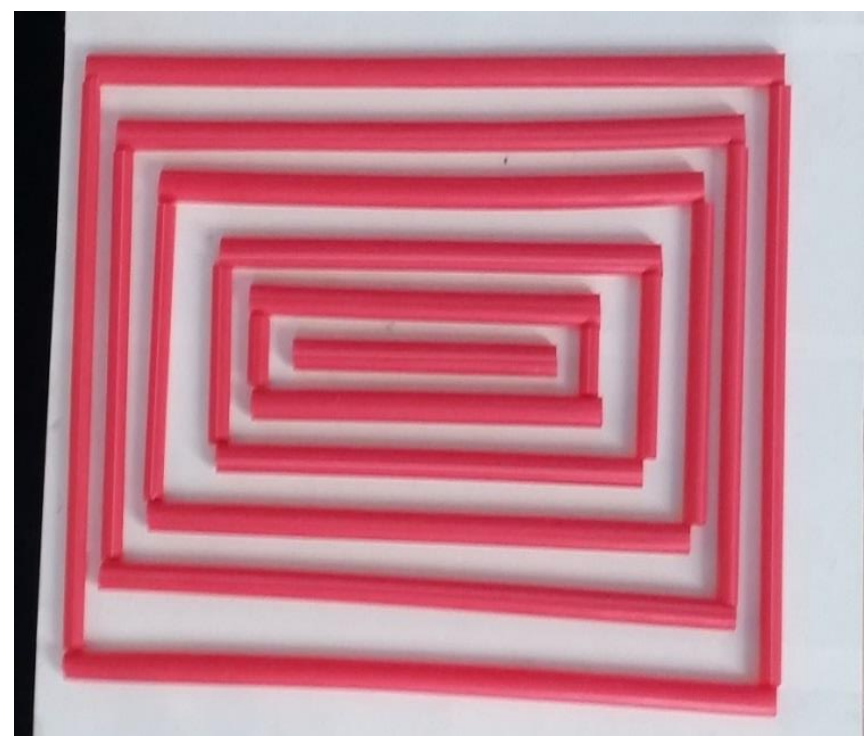

Figura 38 - Processo de construção do grupo 5.

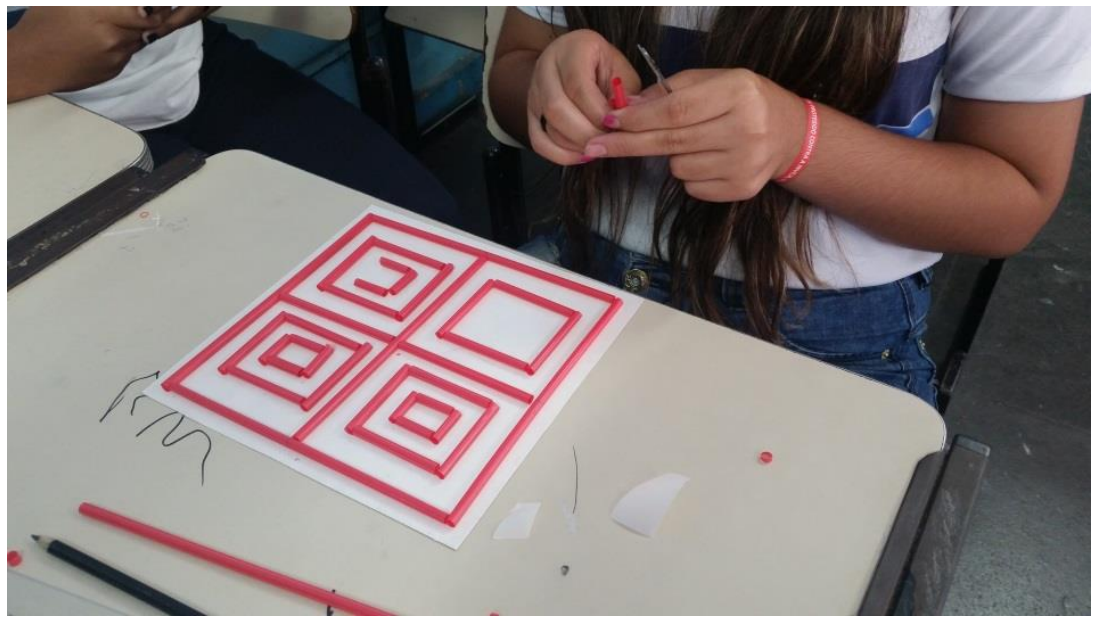

Figura 39 - Produto final do grupo 5.

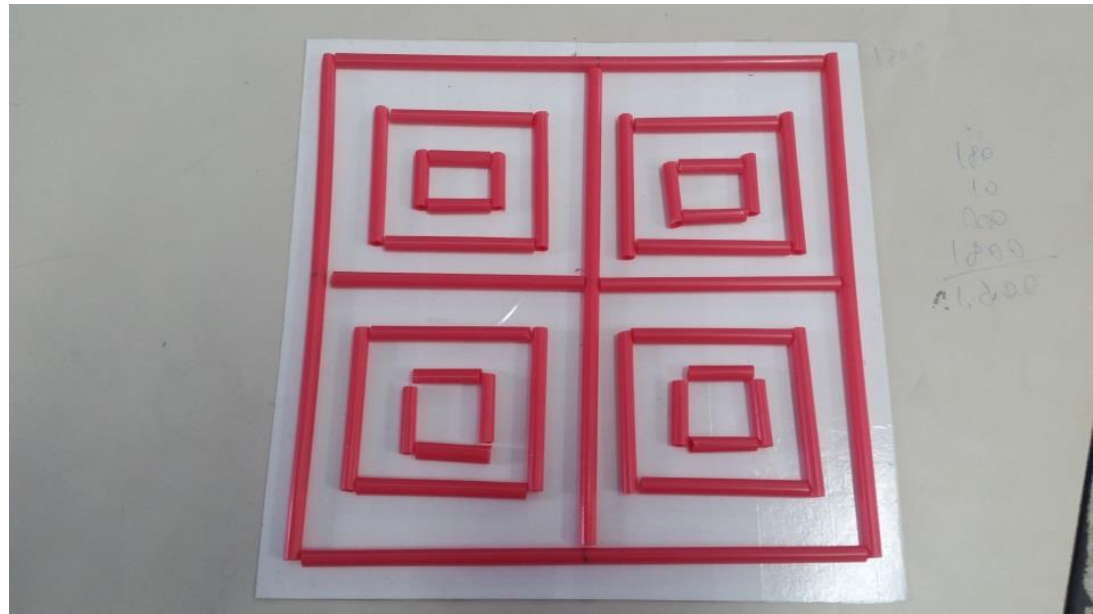


Um valor importante do PROFMAT é tornar seus participantes, multiplicadores do conhecimento. Pensando nisso e com o objetivo de disseminar o tema dos fractais, compartilhamos, na página de facebook da escola, as seis atividades propostas no capítulo anterior. É importante salientar que elas se encontram em constante processo de melhora, podendo sofrer alterações a partir do olhar de outros professores. A página também pode se tornar mais abrangente, com outras contribuições que caminhem na direção de um ensino de matemática mais significativo e motivador.

A divulgação das atividades está disponível no endereço: https://web.facebook.com/emsilvioromero/

Figura 40 - Atividades no facebook da escola.

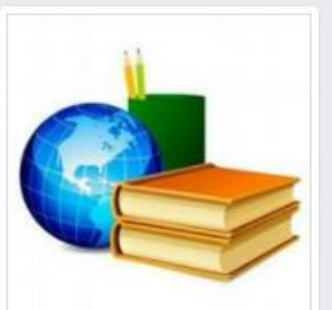

E. M. Silvio Romero (Q)emsilvioromero

Página inicial

Publicações

Avaliações

Fotos

Comunidade

Vídeos

Sobre

Criar uma Página \begin{tabular}{|l|l|l|l|}
\hline If Curtiu & - S Seguindo & $\rightarrow$ Compartilhar & $\cdots$
\end{tabular}

E. M. Silvio Romero adicionou 12 novas fotos. $22 \mathrm{~h} \cdot \mathrm{B}$

Em sua dissertação de Mestrado em Matemática, a professora Vanessa fala sobre a geometria fractal e sua aplicação na educação básica. Para promover essa aplicação, ela elaborou 6 atividades dos mais diversos niveis para os ensinos fundamental e médio. $O$ intuito desta postagem é compartilhar as atividades e incentivar o ensino dos fractais.

Caso você se interesse em obter o arquivo das atividades e sugestões de repostas, entre em contato pelo email:

vanessamoreira@rioeduca.net

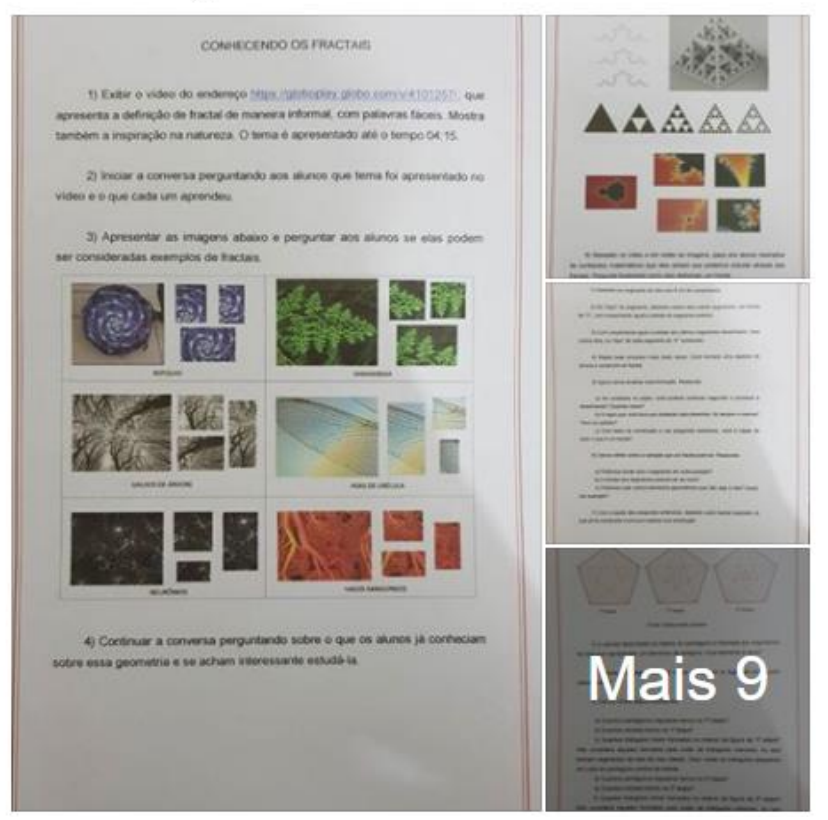




\section{6 \\ Considerações finais}

Atualmente, as escolas possuem muitos alunos desinteressados nos estudos e com poucas perspectivas com relação ao seu futuro. É possível atribuir diversas justificativas a essa realidade: carência de políticas públicas voltadas para uma educação emancipadora, questões socioeconômicas, burocracia administrativa, entre outras. Além disso, cabe ressaltar que o currículo escolar não sofre alterações interessantes que aproximem os conteúdos trabalhados à realidade dos nossos jovens e seus anseios. Assim, em muitas escolas, ainda percebemos corpo docente e discente desmotivados.

Porém, a proposta do presente trabalho é contribuir para que o ensino de matemática possa ser desenvolvido a partir de novas motivações para o alunado. Aproximar os conhecimentos de fenômenos da natureza, mostrar associações com outras áreas do saber, como arte e cultura, e despertar novas curiosidades podem ser maneiras de tornar esse aluno, de fato, protagonista da sua trajetória escolar.

Diante dos conceitos apresentados sobre a geometria dos fractais, é possível perceber sua importância, sua beleza e o quanto de matemática podemos extrair dela, tornando-se, assim, um tema que pode ser desenvolvido em sala de aula com criatividade, prazer e conteúdo.

A experiência relatada mostrou que, mesmo diante das dificuldades, os alunos participaram com mais interesse e ficaram mais abertos a novos aprendizados.

Esperamos que esse trabalho motive os professores dos ensinos fundamental e médio a introduzirem na escola a geometria fractal e a criarem e também divulgarem novas possibilidades para o ensino da matemática. 


\section{7 Referências bibliográficas}

7GRAUS, O que é geometria. Disponível em: <www.significados.com.br>. Acesso em 05 de Janeiro de 2017.

BARBOSA, R.M. Descobrindo a Geometria Fractal para a sala de aula. $3^{\text {a }}$ edição. Belo Horizonte: Autêntica Editora, 2005. 160p.

ENCYCLOPEDIA BRITANNICA, Niels Fabian Helge Von Koch. Disponível em: <global.britannica.com>. Acesso em 29 de março de 2017.

ENCYCLOPEDIA BRITANNICA, Waclaw Sierpinski. Disponível em: <global.britannica.com>. Acesso em 03 de abril de 2017.

FERREIRA, A.B.H. Aurélio: o dicionário da língua portuguesa. Edição especial. Curitiba: Editora Positivo, 2008.

IBM, Fractal Geometry. Disponível em: <www-03.ibm.com/ibm/history/>. Acesso em 10 de abril de 2017.

IEZZI, et al. Matemática - Ciência e Aplicações - Volume 1. 6ª edição. São Paulo: Editora Saraiva, 2010. 304p.

JANOS, M. Geometria Fractal. Rio de Janeiro: Editora Ciência Moderna, 2008. 100p.

LIMA, E.L. et al. Temas e Problemas Elementares. $2^{\underline{a}}$ edição. Rio de Janeiro: SBM, 2005. 256p.

LIMA, E.L. et al. A Matemática do Ensino Médio - Volume 2. 6aㅡ edição. Rio de Janeiro: SBM, 2006. 372p.

MORGADO, A.C.; CARVALHO, P.C.P. Matemática Discreta: Coleção PROFMAT. $1^{\text {a }}$ edição. Rio de Janeiro: SBM, 2013. 204p.

SÓ MATEMÁTICA, Benoit Mandelbrot. Disponível em: <www.somatematica.com.br>. Acesso em 21 de fevereiro de 2017.

SÓ MATEMÁTICA, Georg Cantor. Disponível em: <www.somatematica.com.br>. Acesso em 09 de março de 2017. 


\section{8 Apêndices}

\section{1.}

Sugestões de respostas para a atividade "Desenhando um fractal"

Fractal formado após o item (4):

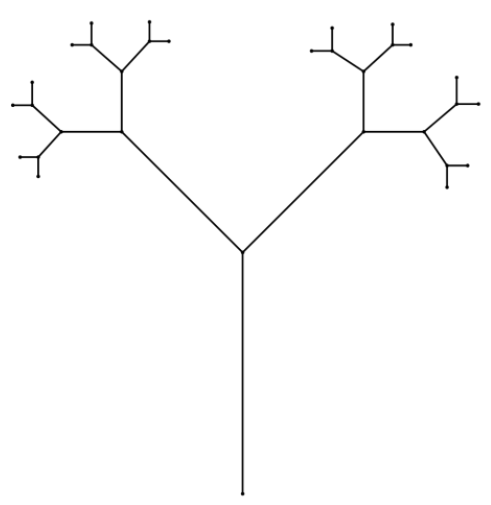

Fonte: Elaboração própria

5) a) Sim. Infinitas vezes. Quantas forem desejadas.

b) Sim.

c) É uma construção formada pela repetição de um padrão, infinitas vezes.

6) a) Sim.

b) Não.

c) Sim. Circunferências, polígonos, curvas etc.

Exemplo de fractal que poderia ser desenhado no item (7):

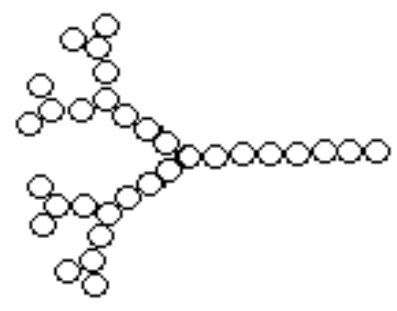

Fonte: Elaboração própria 
8.2.

Sugestões de respostas para a atividade "Pentágonos e estrelas inspirados em fractais"

1) Diagonal.

2) Iniciando com um pentágono, devemos traçar suas diagonais, que formarão uma estrela. Dentro de cada estrela, forma-se outro pentágono e seguimos traçando as diagonais.

3)
a) 2
d) 3
g) 4
b) 1
e) 2
h) 3
c) 10
f) 20
i) 30

4)

\begin{tabular}{|c|c|c|c|}
\hline ETAPA & PENTÁGONOS & ESTRELAS & TRIÂNGULOS \\
\hline 1 & 2 & 1 & 10 \\
\hline 2 & 3 & 2 & 20 \\
\hline 3 & 4 & 3 & 30 \\
\hline
\end{tabular}

5) a) $1 ; n+1$.

b) etapa; $n$.

c) 10;10n.

6)

\begin{tabular}{|c|c|c|c|}
\hline ETAPA & PENTÁGONOS & ESTRELAS & TRIÂNGULOS \\
\hline 5 & 6 & 5 & 50 \\
\hline 20 & 21 & 20 & 200 \\
\hline 431 & 432 & 431 & 4.310 \\
\hline 6.798 & 6.799 & 6.798 & 67.980 \\
\hline
\end{tabular}


8.3.

Sugestões de respostas para a atividade "Quadrados inspirados em fractais"

1) a) $4 \mathrm{~cm}$.

b) FB, BG, GC, CH, HD, DE, EA.

c) Utilizando o Teorema de Pitágoras. $\mathrm{EF}^{2}=4^{2}+4^{2} \rightarrow \mathrm{EF}=4 \sqrt{2} \mathrm{~cm}$.

d) $2 \sqrt{2} \mathrm{~cm}$.

e) JF, FK, KG, GL, LH, HI, IE.

f) $\mathrm{IJ}^{2}=(2 \sqrt{2})^{2}+(2 \sqrt{2})^{2} \rightarrow \mathrm{IJ}=4 \mathrm{~cm}$

g) $2 \mathrm{~cm}$.

h) NJ, JO, OK, KP, PL, LM, MI.

i) $\mathrm{MN}^{2}=2^{2}+2^{2} \rightarrow \mathrm{MN}=2 \sqrt{2} \mathrm{~cm}$.

j) $\sqrt{2} \mathrm{~cm}$.

k) RN, NS, SO, OT, TP, PQ, QM.

l) $\mathrm{QR}^{2}=(\sqrt{2})^{2}+(\sqrt{2})^{2} \rightarrow \mathrm{QR}=2 \mathrm{~cm}$

2)

\begin{tabular}{|c|c|c|c|}
\hline QUADRADO & $\begin{array}{c}\text { LADO DO } \\
\text { QUADRADO }\end{array}$ & $\begin{array}{c}\text { PERÍMETRO DO } \\
\text { QUADRADO }\end{array}$ & $\begin{array}{c}\text { ÁREA DO } \\
\text { QUADRADO }\end{array}$ \\
\hline 1 (ABCD) & $8 \mathrm{~cm}$ & $32 \mathrm{~cm}$ & $64 \mathrm{~cm}^{2}$ \\
\hline $2(\mathrm{EFGH})$ & $4 \sqrt{2} \mathrm{~cm}$ & $16 \sqrt{2} \mathrm{~cm}$ & $32 \mathrm{~cm}^{2}$ \\
\hline $3(\mathrm{IJKL})$ & $4 \mathrm{~cm}$ & $16 \mathrm{~cm}$ & $16 \mathrm{~cm}^{2}$ \\
\hline $4(\mathrm{MNOP})$ & $2 \sqrt{2} \mathrm{~cm}$ & $8 \sqrt{2} \mathrm{~cm}$ & $8 \mathrm{~cm}^{2}$ \\
\hline $5(\mathrm{QRST})$ & $2 \mathrm{~cm}$ & $8 \mathrm{~cm}$ & $4 \mathrm{~cm}^{2}$ \\
\hline
\end{tabular}


3) a) $\frac{\sqrt{2}}{2}$

b) $\frac{\sqrt{2}}{2}$

c) $\frac{1}{2}$

d) São iguais.

e) A razão da área é o quadrado da razão do lado.

4)

\begin{tabular}{|c|c|c|c|}
\hline QUADRADO & $\begin{array}{c}\text { LADO DO } \\
\text { QUADRADO }\end{array}$ & $\begin{array}{c}\text { PERÍMETRO DO } \\
\text { QUADRADO }\end{array}$ & $\begin{array}{c}\text { ÁREA DO } \\
\text { QUADRADO }\end{array}$ \\
\hline $5($ QRST) & $2 \mathrm{~cm}$ & $8 \mathrm{~cm}$ & $4 \mathrm{~cm}^{2}$ \\
\hline 6 & $\sqrt{2} \mathrm{~cm}$ & $4 \sqrt{2} \mathrm{~cm}$ & $2 \mathrm{~cm}^{2}$ \\
\hline 7 & $1 \mathrm{~cm}$ & $4 \mathrm{~cm}$ & $1 \mathrm{~cm}^{2}$ \\
\hline 8 & $\frac{\sqrt{2}}{2} \mathrm{~cm}$ & $2 \sqrt{2} \mathrm{~cm}$ & $\frac{1}{2} \mathrm{~cm}^{2}$ \\
\hline
\end{tabular}




\section{4.}

Sugestões de respostas para a atividade "Circunferências inspiradas em fractais"
1) a) Diâmetro.
b) 5 .
c) 4 .

2) O centro foi o ponto que estava sob a circunferência. A medida do raio foi a medida de uma das partes em que o diâmetro foi dividido.

3) Primeiro dividimos dois diâmetros perpendiculares em quatro partes. Tomando como centro cada ponto sob a circunferência, construímos novas circunferências com raio igual a um quarto do diâmetro anterior, e assim sucessivamente.
4) $(1,4,16, \ldots)$
a) Geométrica.
b) 4
c) $a_{n}=a_{1} \cdot q^{n-1} \rightarrow a_{n}=4^{n-1}$, onde $n$ é a iteração desejada.
d) Exponencial.
e) $S_{n}=\frac{a_{1} \cdot\left(1-q^{n}\right)}{1-q} \rightarrow S_{n}=\frac{4^{n}-1}{3}$, onde $\mathrm{n}$ é a iteração desejada.

5) a) $a_{4}=4^{3}=64$

b) $a_{7}=4^{6}=4.096$

c) $S_{3}=\frac{4^{3}-1}{3}=21$.

d) $S_{6}=\frac{4^{6}-1}{3}=1.365$

6) Opção (b) 


\section{5.}

Sugestões de respostas para a atividade "paralelepípedos inspirados em fractais"

1) Paralelepípedo 1:2 $\times 1 \times 3+2 \times 1 \times 2+2 \times 3 \times 2=22 \mathrm{~cm}^{2}$

Paralelepípedo $2: 2 \times 2 \times 6+2 \times 2 \times 4+2 \times 6 \times 4=88 \mathrm{~cm}^{2}$

Paralelepípedo $3: 2 \times 3 \times 9+2 \times 3 \times 6+2 \times 9 \times 6=198 \mathrm{~cm}^{2}$

2) Paralelepípedo 1: $1 \times 3 \times 2=6 \mathrm{~cm}^{3}$

Paralelepípedo $2: 2 \times 6 \times 4=48 \mathrm{~cm}^{3}$

Paralelepípedo 3: $3 \times 9 \times 6=162 \mathrm{~cm}^{3}$

3) $(1,2,3, \ldots)$

a) Aritmética.

b) 1

c) $a_{n}=1+(n-1) \cdot 1=1+n-1=n$

d) $a_{15}=15 \mathrm{~cm}$

4) $(3,6,9, \ldots)$

a) Aritmética.

b) 3

c) $a_{n}=3+(n-1) \cdot 3=3+3 n-3=3 n$

d) $a_{n}=3.10=30 \mathrm{~cm}$

5) $(2,4,6, \ldots)$

a) Aritmética.

b) 2

c) $a_{n}=2+(n-1) \cdot 2=2+2 n-2=2 n$

d) $a_{n}=2.12=24 \mathrm{~cm}$

6) 9o paralelepípedo:

Altura $=\mathrm{n}=9 \mathrm{~cm}$

Comprimento $=3 \mathrm{n}=27 \mathrm{~cm}$

Largura $=2 \mathrm{n}=18 \mathrm{~cm}$

As dimensões do 9ำ paralelepípedo serão: 9 × $27 \times 18$ 
20ำ paralelepípedo:

Altura $=\mathrm{n}=20 \mathrm{~cm}$

Comprimento $=3 \mathrm{n}=60 \mathrm{~cm}$

Largura $=2 \mathrm{n}=40 \mathrm{~cm}$

As dimensões do $20^{\circ}$ paralelepípedo serão: 20 × 60 × 40

7) Funções do $1^{\circ}$ grau. Crescentes.

8)

\begin{tabular}{|c|c|c|c|}
\hline DIMENSÃO & FUNÇÃO & $\begin{array}{c}\text { COEFICIENTE } \\
\text { ANGULAR }\end{array}$ & $\begin{array}{c}\text { TERMO } \\
\text { INDEPENDENTE }\end{array}$ \\
\hline Altura & $a_{n}=n$ & 1 & 0 \\
\hline Comprimento & $a_{n}=3 n$ & 3 & 0 \\
\hline Largura & $a_{n}=2 n$ & 2 & 0 \\
\hline
\end{tabular}

